\title{
Hexagrid-Voronoi transition in structural patterns for tall buildings
}

\author{
Elena Mele, Massimiliano Fraldi, Gian Maria Montuori, Gianpaolo Perrella, Vincenzo Della Vista \\ University of Naples Federico II, Italy \\ elenmele@unina.it, bttp:/ /orcid.org/0000-0002-1815-0643
}

\begin{abstract}
In this paper, a first insight into the role that non-conventional structural patterns might play in the design of tall buildings is presented. The idea is to explore the mechanical properties of selected non-conventional structural patterns, in the form of both regular (Hexagrid) and irregular (Voronoi tessellation inspired) arrays, in order to assess their actual applicability in tall building design. For this aim, the concept of Representative Volume Element (RVE) and a classical homogenization-based micromechanical approach are employed for identifying the pattern units and deriving the relevant generalized stress-strain relationships. In the case of irregular patterns based on Voronoi diagrams, obtained by perturbing prescribed key geometrical features of hexagrids, a statistically significant sample of RVEs is defined on the basis of sensitivity analyses, and the related mechanical characterization is developed in statistical terms. Finally, a preliminary stiffness-based design procedure is proposed and applied to a tall building model with Voronoi exoskeleton. In conclusion, a discussion on the effectiveness of the design procedure and on the structural efficiency of the Voronoi patterns for tall buildings is presented.
\end{abstract}

KEYwORDS. Voronoi; Hexagrid; Steel Structure; Homogenization Method; Stiffness Design.

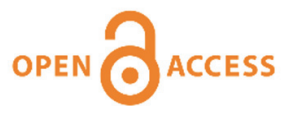

Citation: Mele, E., Fraldi, M., Montuori, G.M., Perrella, G., Della Vista, V. Nonconventional structural patterns for tall buildings: from diagrid to hexagrid and beyond, Frattura ed Integrità Strutturale, 47 (2019) 186-208.

Received: 06.08.2018

Accepted: 04.10 .2018

Published: 01.01.2019

Copyright: (C) 2019 This is an open access article under the terms of the CC-BY 4.0, which permits unrestricted use, distribution, and reproduction in any medium, provided the original author and source are credited.

\section{INTRODUCTION}

7 he fundamental conceptual simplification for the structural design of tall buildings, "the idea" [1], consists in considering the building as a giant cantilever beam, with overturning moment and shear force known a priori, and global horizontal deformation at the building top given by a combination of flexural and shear contributions, i.e.:

$$
\delta_{t o p}=\delta_{f l e x .}+\delta_{s b .}=\frac{q H^{4}}{8 E I}+\chi \frac{q H^{2}}{2 G A}
$$


where: $\mathrm{q}$ is the uniform horizontal load, representative of the wind action, $\mathrm{H}$ is the beam length (i.e. the building height), $\mathrm{A}$ and $I$ are respectively the area and the moment of inertia of the beam cross section, $\mathrm{E}$ and $\mathrm{G}$ are respectively the material axial and shear moduli, $\chi$ is the shear factor. A stiffness based criterion for preliminary sizing the cross section (area and inertia) of the equivalent beam consists in setting a limit value for the top displacement, e.g.:

$$
\delta_{\text {top, lim }}=\frac{H}{500}
$$

For a vertical cantilever beam under transversal loads coming from any horizontal directions, the concept that ensures the maximization of bending strength and stiffness is the centrifugation of areas, thus the ideal cross section is a hollow section. The structural configuration of tall buildings best reflecting this optimal section shape of the equivalent cantilever beam is the tube. In this configuration, in fact, the building facades othogonal to the load direction act as the flanges of the hollow cross section, counteract overturning moment through axial tension and compression, and provide the bending stiffness by mobilizing the axial stiffnesses. The facades parallel to load direction provide shear resistance; however, since the building facades are usually made of a grid of structural members instead of solid panels, the shear-resisting mechanism and deformation mode of the façade grid strongly affects the tube efficiency. In this perspective, diagrid structures - the latest mutation of tube structures - show an extraordinary efficiency, related to the adopted geometrical pattern: thanks to the triangle tessellation of the façades, internal axial forces are largely prevalent in the structural members, thus shear lag effects and racking deformations are minimized [2]. Being also adaptable to any surface, the diagrid tube is becoming the most used structural solution for tall buildings of complex form $[3,4,5]$.

However, alternative, non conventional, geometrical patterns are worth of consideration for their structural and aesthetical qualities. Natural patterns, i.e. geometrical patterns observable in nature which reflect the unquestionable laws of economy and efficiency $[6,7]$, can be a fruitful and almost endless source of inspirations for efficient man-made structures, at all scale levels (from the very tiny - material design - to the biggest - tall buildings - embracing all intermediate steps).

In the context of material science and engineering, heterogeneous and cellular materials, as well as hierarchical natural organisms, have been intensely studied in the last decades $[8,9,10]$ and have inspired the biomimicry approach for the conception and fabrication of man-made products. An example is the adoption of hexagon-based configurations for creating honeycomb structure, which results in composite materials with minimal density and relative high compression and shear properties, thereby obtaining high efficiency (strength - or stiffness - to weight ratio).

The lesson of the nature has been transposed in different ways and at different extents in the engineering design disciplines: while composite materials, foam structures, sandwich panels are typical applications at the material-scale level, a more superficial and incomplete awareness of the efficiency philosophy taught by nature can be found at macro-scale level, in the context of civil engineering. In particular, the structural designers operating in the field of building engineering is less prone to explore ideas coming from natural structures and to experiment novel bio-inspired structural systems.

Actually, some suggestions in this direction come from the architecture realm, with a stunning variety of proposals, projects, visions, more or less consciously inspired by natural structures, such as foams, seashells, radiolariae, glass sponge, bone tissue, coral or cactus skeletons, etc. It is worth noticing that the above patterns are often based on non regular hexagonal meshes, that can be represented by Voronoi diagrams [11, 12]. In Fig. 1 is shown a collection of tall buildings inspired by natural patterns, mainly concerning architecture proposals in design competitions.

The design, modelling and analysis of such structural patterns are neither as familiar as in the case of the traditional orthogonal pattern (the beam/column frame) nor as straightforward as in the case of the simple triangular pattern (the diagrid structure). Therefore, a challenging and exciting task for the research in structural engineering is to find an approach for dealing with any structural patterns, trying to bridge the gap between design visions and actual constructability.

In this perspective, the authors have undertaken a wide research activity starting from the idea that natural structures, as well as cross-fertilization between science and engineering, can inspire also man-made products at the mega level, namely structures for high-rise and long-span buildings, thus providing a radically new repertoire of forms and systems for challenging architectures. As a first step of the research undertaken by the authors, hexagon-based patterns are here examined as tube structural grids for tall buildings. Objects of the study are both regular and non-regular patterns: the formers are patterns made by uniform tessellation of hexagonal cells, appointed as hexagrids, while the latters, the non regular patterns, are either fully based on Voronoi diagrams, or mixed regular (hexagrids) and irregular (Voronoi) patterns. In the paper [13] the authors have focused attention on regular horizontal hexagrids (i.e. hexagonal patterns made by horizontal and diagonal structural members). Major aims of the paper [13] were: the investigation of the structural properties of hexagrids; the assessment of their applicability in tall buildings; the definition of a simple design procedure for the 
preliminary sizing of the structural members composing the hexagonal pattern; the comparison of their potential efficiency to the more popular diagrid systems.

In the present paper, non regular patterns based on Voronoi diagrams are considered for structural grid of tall building façades, thus obtaining Voronoi tube structures. In the following, the objective and approach utilized in the paper are stated; the geometrical definition of Voronoi diagram is introduced, and the procedure for the generation of Voronoi diagrams is explained; the general methodology for the mechanical characterization and the homogenization process of structural grids is presented and applied to regular hexagrid; the additional steps required for a non-regular, Voronoi-like grid, are provided and discussed; finally a design procedure is proposed and applied to a model building, which gives the opportunity of discussing both the effectiveness of the procedure here proposed and the structural efficiency of Voronoi patterns.
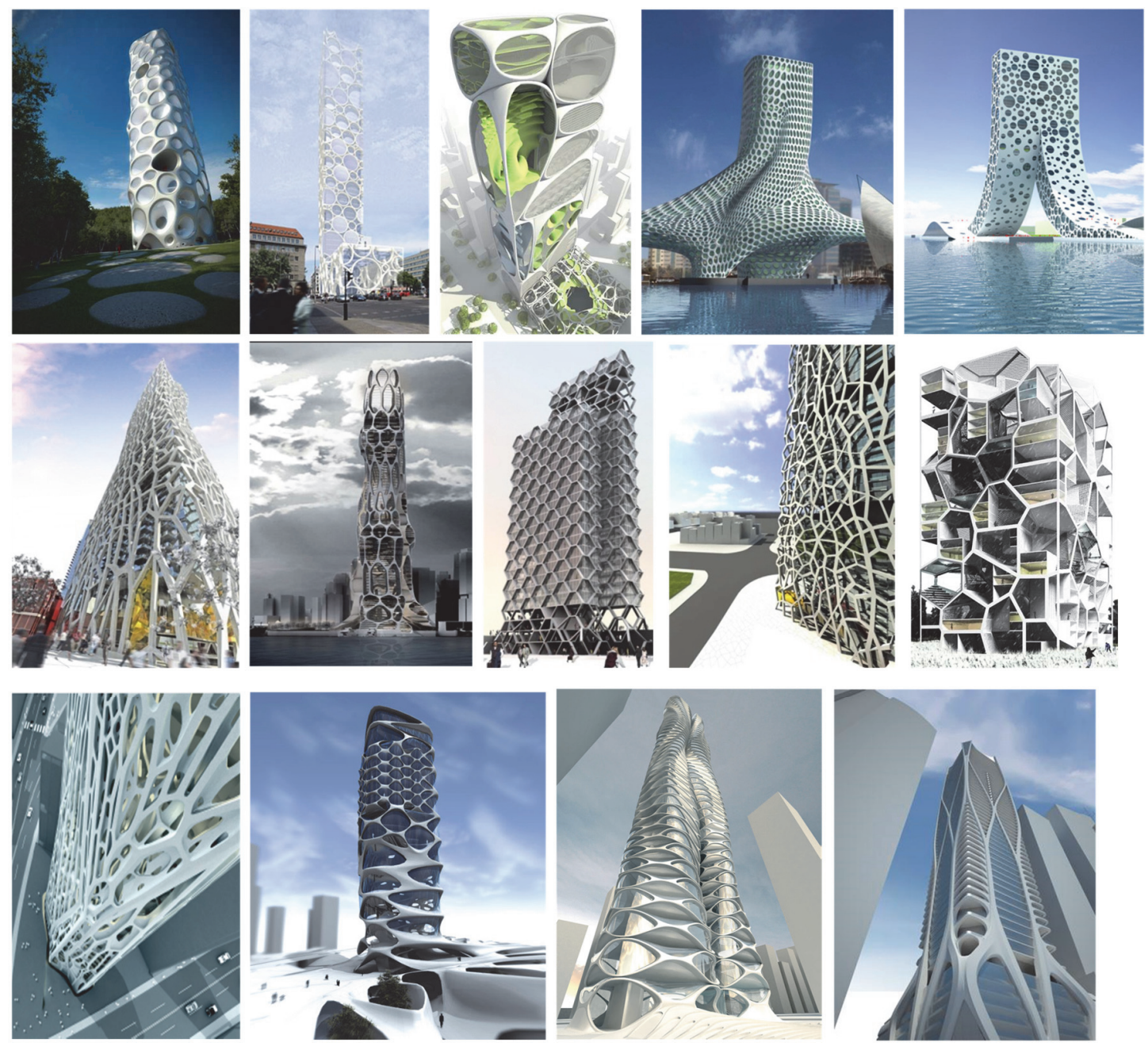

Figure 1: Examples of non-conventional structural patterns.

\section{OBJECTIVE OF THE WORK AND METHODOLOGY}

$\mathrm{W}$ ith reference to the stiffness based design criterion expressed through Eqs. (1-2), an appropriate procedure for taking into account the discrete nature of the structural grids (acting as flanges and webs of the equivalent beam cross section) should be defined, in order to preserve the conceptual scheme of equivalent cantilever beam; in other words, in the Eq. (1) appropriate values (EI) grid and (GA) grid should be substituted to EI and GA:

$$
\delta_{\text {top }}=\delta_{\text {flex. }}+\delta_{s b .}=\frac{q H^{4}}{8(E I)_{\text {grid }}}+\chi \frac{q H^{2}}{2(G A)_{\text {grid }}}
$$


This approach has been proposed by [13] for dealing with frame tube structures: the beam-column patterns of the building façades are considered equivalent to orthotropic membranes, thus the framed tube can be analyzed as an equivalent solid tube.

A more general methodology is proposed in this paper for dealing with grid-like structures: the idea is to model whichever grid as a continuous depleted medium, characterized by penalized mechanical properties, according to the classical micromechanical approach based on homogenization methods [14]; the macroscopic penalized properties of the structure, appointed as effective properties, will account for both the mechanical properties of the solid matrix and the micro-structural features of the grid, namely topology, density, orientation.

Basically, the procedure consists in evaluating the effective axial and shear moduli of the grid, which account for the geometric and elastic properties of structural members as well as for the geometrical pattern of the grid. Once the effective axial stiffness and racking shear stiffness of the grid are evaluated, the standard formulae defined for a solid tube can be utilized for calculating the horizontal deflections of the homogenized tube (Eq. 3); that is, the stiffness based design criterion for a tube tall building (Eq. 2) can be specified substituting EI and GA with (EI) grid and (GA)grid (Eq. 3), and the member cross section properties required for satisfying the limit deflection $\left(\delta_{\text {top }}=\mathrm{H} / 500\right)$ can be obtained.

This is the approach already adopted in [12] for regular hexagonal grids, where the mechanical characterization and the consequent homogenization of the grid consists in the assessment of the structural behaviour of a simple, unit cell (the Representative Volume Element, RVE, of the grid), easily identifiable thanks to the grid regularity and periodicity.

In this paper the approach is extended to the case of irregular grids, namely a grid obtained from the Voronoi diagram; in this extension, a first difficulty arises in the identification of the unit cell, which, quite trivially, does not exist due to the irregularity, non-periodicity and randomness of the grid.

The approach here proposed for overcoming such difficulty consists in defining the correlation between the average mechanical properties of the irregular (Voronoi) patterns and regular (hexagrid) counterparts on a statistical basis; the aim is to define the appropriate correction factors which allow for calculating the average mechanical proprieties of the Voronoi patterns, known the ones of a reference regular pattern.

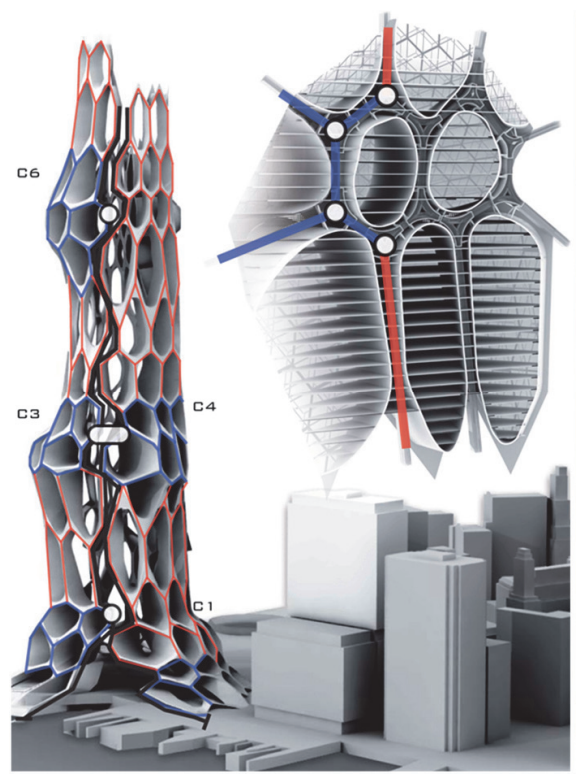

a)

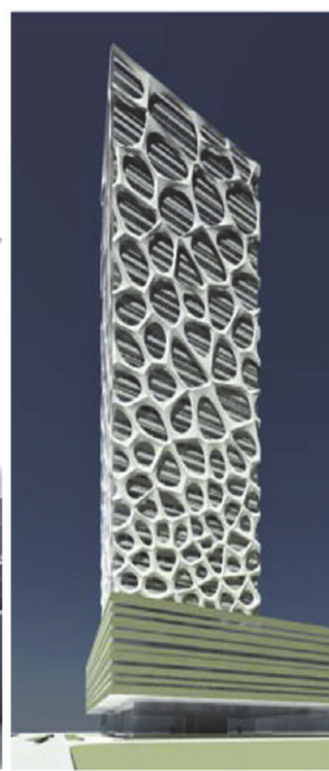

b)

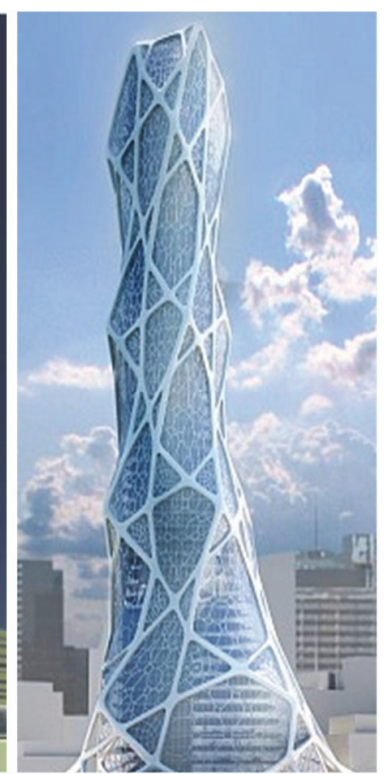

c)

Figure 2: Voronoi patterns for tall buildings: a) "Use Arrangement" Christian Hahn eVolo 2010 Skyscraper competition entry; b) SOM competition entry for a tower in Tianjin; c) Lava Bionic Tower.

\section{VORONOI DIAGRAMS: GEOMETRY AND GENERATION}

Geometric definition

he Voronoi diagram (or tessellation) is the mathematical explanation for a visual pattern often found in nature, as in the structure of leaves, in the skin of animals, and in several life forms. In mathematics, "a Voronoi diagram is 
the division of a space into contiguous neighbouring cells, which relate to a set of points (Voronoi sites) in that space; each point has an associated cell consisting of all the points closer to that site than any other" [15]

For the construction of the Voronoi diagram, a set of points (appointed as seeds, sites, or generators) should be defined; then, for each seed, a corresponding region (appointed as Voronoi cell) is obtained as the one consisting of all points closer to that seed than to any other. The Voronoi construction can be carried out both on a plane, giving rise to two-dimension Voronoi tiling, and in the space, giving rise to three-dimension Voronoi tessellations.

Theoretical and practical applications of Voronoi diagrams cover several fields of science and technology, going from astrophysics, epidemiology, geometry, networking, hydrology, meteorology, ecology, computer graphics, computational fluid dynamics, etc. [16]. In particular, Voronoi tessellations are widely used in the context of material science, for representing polycrystalline microstructures of metallic alloys [17], and in the field of biology, for modelling different natural structures, including cells and bone microarchitecture [18]; in the framework of material engineering and design, the Voronoi diagram is the major approach for modelling and analyzing cellular solids and solid foams [19, 20].

The Voronoi diagram and its numerous generalizations for the division of space are a rich source of ideas and schemes for the design of spatial structures which has inspired many architects. The concept works in the plane, with seeds on a surface, as well as in space, as can be seen from the skyscraper proposals provided in Fig. 2. The schems in Fig. 2a [21], Fig. 2b [22] and Fig. 2c [23] explicitly refer to both 3D and 2D Voronoi tessellations; in particular it can be observed that the project represented in Fig. 2a utilizes the Voronoi partition as a 3D strategy for space subdivision, that can be an interesting conceptual approach for unifying form, function and structure in the building design.

\section{Voronoi tessellation}

Several methods [24-27] are reported in the scientific literature for the generation of the Voronoi tessellation. The method proposed in [28] is used in the following, since it allows for controlling the irregularity degree of the Voronoi diagram.

The starting point is a regular geometry, obtained by applying the Voronoi construction to a regular grid of seeds; in particular in this paper, regular hexagonal patterns are considered as initial geometries. Fig. 3 shows how regular honeycomb can be generated from seeds arranged at the vertexes of equilateral triangles (i.e. according to a Delaunay tessellation, which is dual to Voronoi diagram).

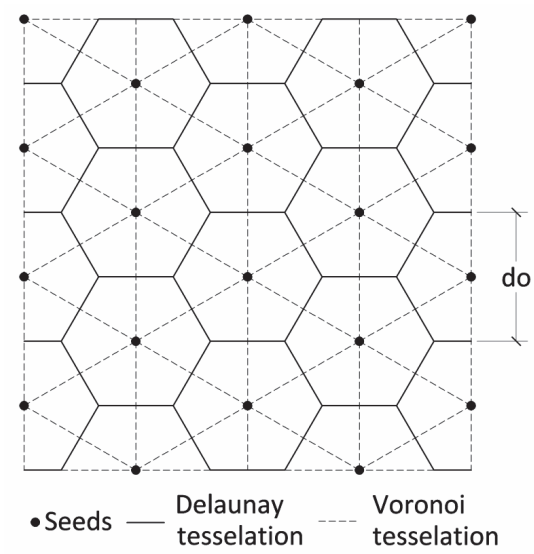

Figure 3: Voronoi construction applied to Delaunay disposition of seeds.

The second step is to modify randomly the regular array of seeds; for this aim, the coordinates $\left(\begin{array}{l}-\mathrm{x}_{1},-\mathrm{s} \\ \mathrm{x}_{1}, \mathrm{x}_{2}\end{array}\right)$ of the generic seed $s$ are perturbed (Fig. 4) through two random variables $\vartheta_{\mathrm{s}} \in[0,2 \pi]$ and $\varphi_{\mathrm{s}} \in[-1,1]$. The variable $\vartheta_{\mathrm{s}}$ is a random angle between the $\mathrm{x}_{1}$ axis and the line connecting the perturbed and the non perturbed position of the seed $s$; it is assumed to be distributed according to an uniform distribution, with the following probability density function:

$$
\mathrm{P}_{\vartheta}\left(\vartheta_{s}\right)= \begin{cases}1 / 2 \pi & 0 \leq \vartheta_{\mathrm{s}} \leq 2 \pi \\ 0 & \vartheta_{\mathrm{s}}<-1, \vartheta_{\mathrm{s}}>1\end{cases}
$$

The variable $\varphi_{\mathrm{s}}$ is a random scale factor, with uniform distribution and the following probability density function: 


$$
\mathrm{P}_{\varphi}\left(\varphi_{s}\right)= \begin{cases}1 / 2 & -1 \leq \varphi_{\mathrm{s}} \leq 1 \\ 0 & \varphi_{\mathrm{s}}<-1, \varphi_{\mathrm{s}}>1\end{cases}
$$

Therefore the perturbed coordinates $\left(\mathrm{x}_{1}^{\mathrm{s}}, \mathrm{x}_{2}^{\mathrm{s}}\right)$ are defined by using the following equations:

$$
\begin{aligned}
& \mathrm{x}_{1}^{\mathrm{s}}=\overline{\mathrm{x}}_{1}^{-\mathrm{s}}+\alpha\left(\mathrm{d}_{0} \operatorname{Cos} \vartheta_{\mathrm{s}}\right) \cdot \varphi_{\mathrm{s}} \\
& \mathrm{x}_{2}^{\mathrm{s}}=\stackrel{-\mathrm{s}}{\mathrm{x}_{2}}+\alpha\left(\mathrm{d}_{0} \operatorname{Sin} \vartheta_{\mathrm{s}}\right) \cdot \varphi_{\mathrm{s}}
\end{aligned}
$$

where $\alpha \in[0,1]$ defines the irregularity degree of the Voronoi grid, namely $\alpha=0$ corresponds to the regular hexagonal grid, while $\alpha=1$ corresponds to Voronoi grid with maximum degree of irregularity.

The last step is to apply the Voronoi tessellation rule to the arrays of points modified through the Eqns. (6) and (7), in order to obtain patterns with irregularity governed by the value of the parameter $\alpha$. The fundamental role played by $\alpha$ is clearly shown in Fig. 5, which provides three specimens with the same overall dimensions and number of seeds (i.e. of initial hexagons), but with different degree of irregularity, i.e. different values of $\alpha$ adopted in the generation process.

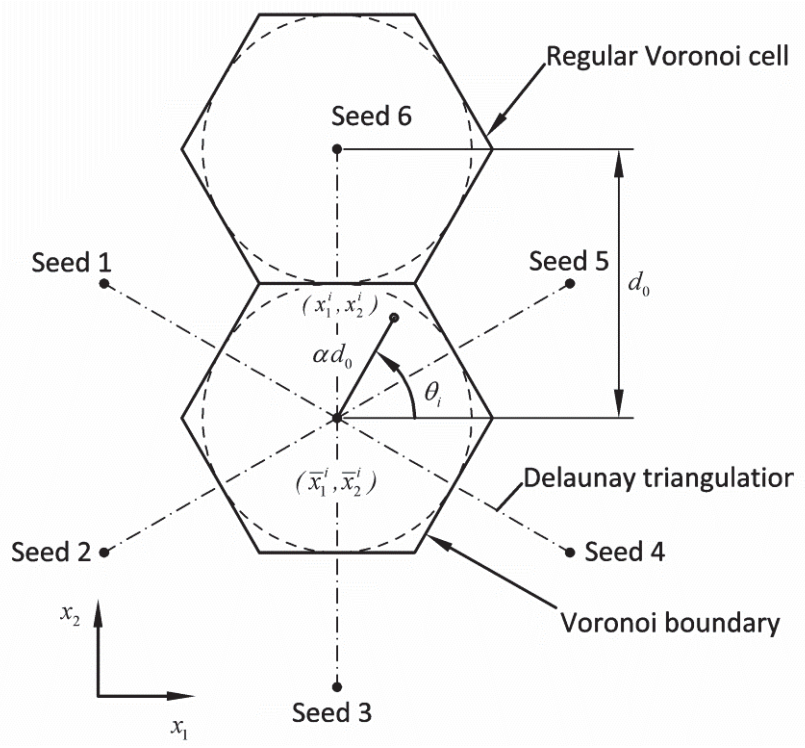

Figure 4: Geometric perturbation of the coordinates of regular array of seeds.

For $\alpha=0$, a regular honeycomb structure is generated; increasing $\alpha$, the irregularity of the pattern increases, and for $\alpha=1$, a geometry with the maximum irregularity degree is obtained. Of course, for each values of $\alpha$ (i.e. for each level of irregularity), infinite geometric configurations can be generated varying the random parameters $\varphi_{\mathrm{s}}$ and $\vartheta_{\mathrm{s}}$.

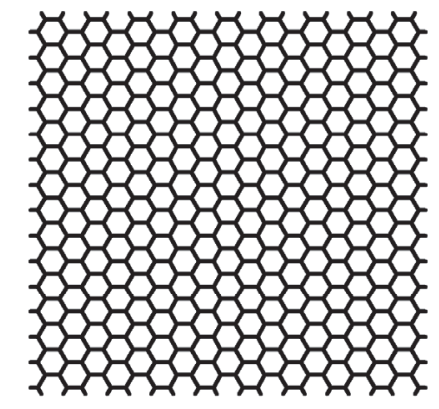

$\alpha=0.0$

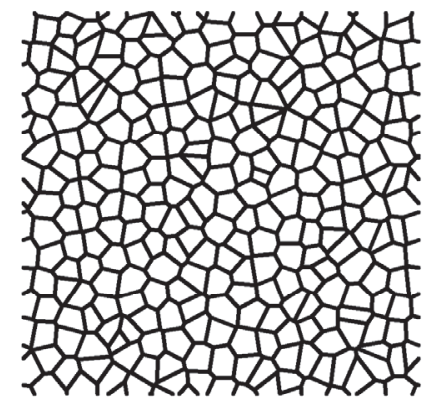

$\alpha=0.5$

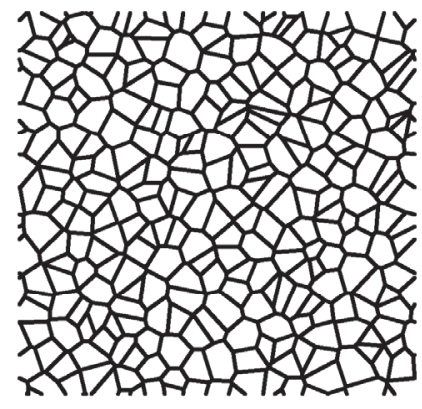

$\alpha=1.0$

Figure 5: Effect of the irregularity parameter $\alpha: \alpha=0 ; \alpha=0.5 ; \alpha=1$. 
The process described to generate the Voronoi geometries has been automated by implementing a specific algorithm in Grasshopper environment (Rhinoceros 3D®). The algorithm is made by clusters of functions which allow to: i) create a regular arrangement of seeds (as shown in Fig. 3); ii) set the required irregularity level; iii) alter the coordinates of the seed by means of the Eqs. (6-7), using two different random engines for the two random variables, $\varphi_{\mathrm{s}}$ and $\vartheta_{\mathrm{s}}$; iv) generate the Voronoi geometry, i.e. the polygonal cells, from the perturbed seeds. Using this algorithm, a large number of samples can be generated with a rigorous method and with low time consumption.

\section{MECHANICAL APPROACH FOR REGULAR AND IRREGULAR PATTERNS}

$\mathrm{I}$ $\mathrm{n}$ order to apply the design procedure described in the previous paragraph, the correlation between the geometrical characteristics of the irregular Voronoi patterns and the mechanical properties of the homogenized material should be identified. The idea is to use the typical approach estalished in the field of cellular materials, in which the mechanical properties of cellular solids are calculated by defining an ideal unit cell (i.e. the geometric unity that through replication allows to obtain the overall geometric pattern without overlaps or gaps). For examples, hexagonal cells are used to describe many $2 \mathrm{D}$ honeycomb-like cellular solids, while cubic, tetrahedral and dodecahedral solid are used for tridimensional cellular materials. Using these simplified unit cells, the relationships between the microstructure and the overall mechanical proprieties (e.g. relative density, axial and shear stiffness) can be derived in closed form [27, 8, 29]. As already mentioned, a similar approach, though applied to a rectangular orthogonal pattern, was used in [13] for the design of framed tube structures, and more recently in [30] and [12] for the design and analysis of hexagrid and diagrid tube structures.

In the following a brief description of the overall mechanical proprieties useful for the design process, is reported.

The overall mechanical response can be obtained starting from the unit cell; in particular, it is necessary to introduce the socalled Representative Volume Element (RVE), which is defined as the smallest homogeneous material volume which macroscopic constitutive relationships must be referred to [31]; therefore the RVE can be considered as the structural idealization of the unit cell.

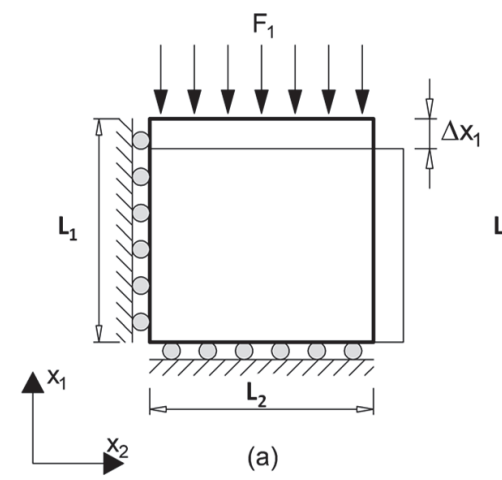

(a)

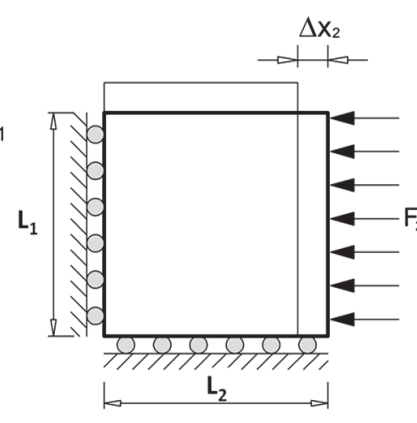

(b)

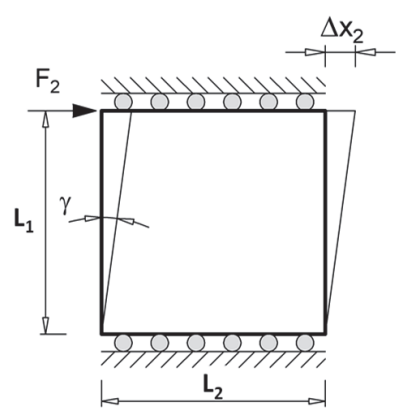

(c)

Figure 6: RVE mechanical tests: a) axial test along $\mathrm{x}_{1}$; b) axial test along $\mathrm{x}_{2}$; c)shear test.

Once defined the RVE, the effective mechanical properties of the $2 \mathrm{D}$ structural grid, $\mathrm{E}_{1}{ }^{*}, \mathrm{E}_{2}{ }^{*}, \mathrm{G}_{12}{ }^{*}$ and $\mathrm{G}_{21}{ }^{*}$ can be obtained by means of numerical deformation tests carried out on the RVE. In particular, the elastic axial modulus $\mathrm{E}_{1}{ }^{*}\left(\mathrm{E}_{2}{ }^{*}\right)$ is defined as the ratio of the uniaxial normal stress $\sigma_{1}\left(\sigma_{2}\right)$ divided by the uniaxial strain $\varepsilon_{1}\left(\varepsilon_{2}\right)$ in the elastic range, obtained for the reference specimen (the RVE) subject to simple axial load, as illustrated in Fig. Ga for the load direction $\mathrm{x}_{1}$, and in Fig. 6b, for the load direction $\mathrm{x}_{2}$. Normal stress is the average normal force $\left(\mathrm{F}_{1}\right.$ or $\left.\mathrm{F}_{2}\right)$ acting perpendicularly on a surface of area ( $\mathrm{L}_{2} \mathrm{xb}$, or $\left.\mathrm{L}_{1} \mathrm{xb}\right)$. Strain is the shortening/lengthening $\left(\Delta \mathrm{x}_{1}\right.$ or $\left.\Delta \mathrm{x}_{2}\right)$ of the RVE divided by the initial length $\left(\mathrm{L}_{1}\right.$ or $\left.\mathrm{L}_{2}\right)$ in the loading direction.

$$
\mathrm{E}_{1}^{*}=\frac{\sigma_{1}}{\varepsilon_{1}}
$$

where: $\sigma_{1}=\frac{\mathrm{F}_{1}}{\mathrm{~L}_{2} \cdot \mathrm{b}}$ and $\varepsilon_{1}=\frac{\Delta \mathrm{x}_{1}}{\mathrm{~L}_{1}}$. The axial modulus $\mathrm{E}_{2}{ }^{*}$ can be easily obtained following the same procedure. 
The shear modulus $\mathrm{G}_{12}{ }^{*}$ represents the elastic modulus used to describe, in the plane $\left\{\mathrm{x}_{1}, \mathrm{x}_{2}\right\}$ the relationship between the deformation that occurs in the RVE when it is subject to a couple of forces, parallel to one of its edges, as illustrated in Fig. 6c. It is the ratio of the shear stress $\tau$ divided by the shear strain $\gamma$. Shear stress is the force $F_{2}$ applied parallel to the edge with normal 1 along direction 2, divided by the area, $\mathrm{L}_{2} \mathrm{xb}$. The shear strain, for small deformation, can be defined as the transverse displacement $\Delta \mathrm{w}$ divided by the initial length $\mathrm{L}_{1}$.

$$
\mathrm{G}_{12}^{*}=\frac{\tau}{\gamma}
$$

where: $\tau=\frac{\mathrm{F}_{2}}{\mathrm{~L}_{2} \cdot \mathrm{b}}$ and $\gamma=\frac{\Delta \mathrm{w}}{\mathrm{L}_{1}}$. The shear modulus $\mathrm{G}_{21}{ }^{*}$ can be easily obtained following the same procedure.

It is necessary to underline that, while for regular patterns the RVE can be explicitly identified and analysed for defining the expressions of $\mathrm{E}_{1}{ }^{*}, \mathrm{E}_{2}{ }^{*}, \mathrm{G}_{12}{ }^{*}$ and $\mathrm{G}_{21}{ }^{*}$ in closed form, this is not possible for the patterns derived from the Voronoi tessellation, due to their inherent irregularity, non periodicity and randomness. The approach here proposed consists in defining the correlation between the mechanical properties of the irregular (Voronoi) and regular (hexagrid) patterns, the former obtained from the latter through Eqs. (6-7) for $\alpha \neq 0$. The aim is to define appropriate correction factors $\eta_{E i}$ and $\eta_{\text {Gij }}$, such that:

$$
\eta_{\mathrm{Ei}}=\frac{\mathrm{E}_{\mathrm{i}, \mathrm{V}}^{*}}{\mathrm{E}_{\mathrm{i}, \mathrm{H}}^{*}}, \eta_{\mathrm{Gij}}=\frac{\mathrm{G}_{\mathrm{ij}, \mathrm{V}}^{*}}{\mathrm{G}_{\mathrm{ij}, \mathrm{H}}^{*}}
$$

where the subscripts $\mathrm{H}$ and $\mathrm{V}$ refer, respectively, to the regular hexagrid and the corresponding Voronoi grid, generated starting from the regular hexagrid. The ratios $\eta_{\mathrm{Ei}}, \eta_{\mathrm{Gij}}$ allow for calculating the mechanical proprieties of the Voronoi pattern characterised by a specific value of the irregularity factor, $\alpha$, starting from the ones of the "original" honeycomb pattern, characterized by the same number of seed points.

In the following, the procedure for obtaining the mechanical properties of a regular honeycomb is briefly recalled from [12]; subsequently, the procedure for deriving the correction factors for the Voronoi counterpart is described.

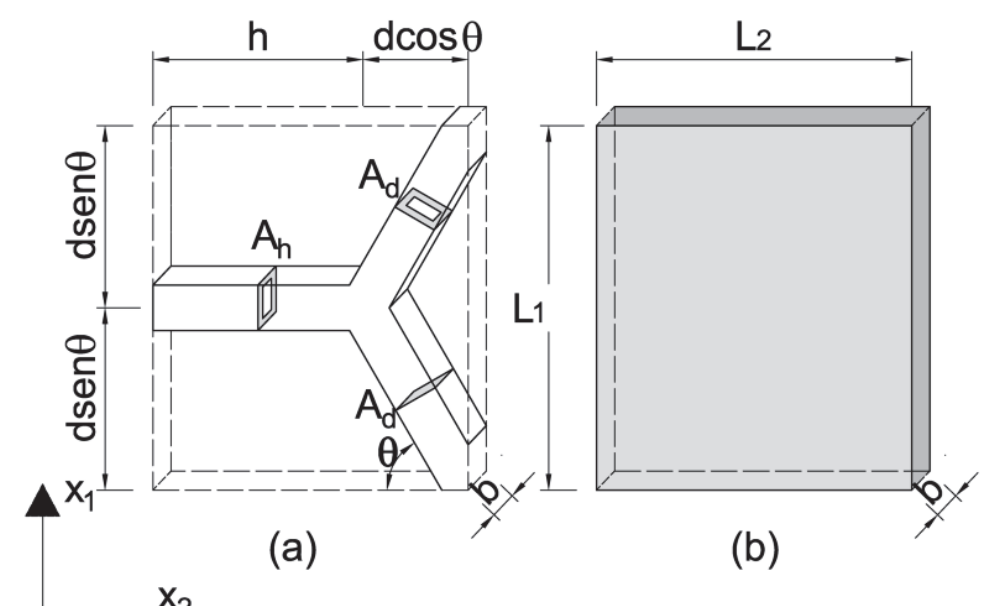

Figure 7: Hexagrid. Definition of the relative density for the unit cell.

\section{MECHANICAL PROPRIETIES OF THE REGULAR HONEYCOMB}

$\mathrm{T}$

he Relative Density @ is an important scalar geometrical quantity, defined as the ratio of the volume occupied by the solid material, $Q^{*}$, to the total volume of the cell, $\varrho_{\text {vol. }}$ For the unit cell of a $2 \mathrm{D}$ grid made of one dimensional beam elements (see Fig. 7), the definition of $\varrho$ becomes: 


$$
\varrho=\frac{\varrho^{*}}{\varrho_{\text {vol }}}=\frac{\sum_{\mathrm{i}=1}^{\mathrm{n}} \ell_{\mathrm{i}} \mathrm{A}_{\mathrm{i}}}{\mathrm{L}_{1} \mathrm{~L}_{2} \mathrm{~b}}
$$

where $n$ is the total number of beams in the unit cell, $l_{i}$ and $A_{i}$ are respectively the length and the cross section area of beams, $\mathrm{L}_{1}$ and $\mathrm{L}_{2}$ are the dimensions of the $2 \mathrm{D}$ unit cell along the directions $\mathrm{x}_{1}$ and $\mathrm{x}_{2}, \mathrm{~b}$ is the thickness of the unit cell, i.e. the width of the beam cross section.

For a regular hexagrid, the relative density, generically defined by means of Eq. 11, can be further specialised according to the following equation (Fig. 7):

$$
\varrho=\frac{\left(h A_{h}\right)+\left(2 d A_{d}\right)}{[(h+d \operatorname{Cos} \theta)(2 d \operatorname{Sin} \theta)] b}
$$

where: $h$ and $d$ are the lengths of the horizontal and diagonal beams, respectively; $A_{h}$ and $A_{d}$ are the cross section areas of the horizontal and diagonal beams; $\theta$ is the angle between the diagonal element and the horizontal axis. Considering a regular hexagonal grid, the RVE can be easily established by looking at the deformation modes and internal force distributions arising in the unit cell as a part of the global grid, under axial and shear tests. Figs. 8, 9, 10 and 11 show the static models of the RVE, adopted for carrying out the axial and shear tests; more details can be found in [12].

In the axial test, the global axial deformation of the RVE is given by the contributions of (local) bending, axial and shear deformations of the RVE structural members. Therefore the stiffness of the hexagrid in the direction $\mathrm{x}_{1}, \mathrm{E}_{1 \mathrm{H}}^{*}$, (Fig. 8) normalised to the Young's modulus of the member solid material $\mathrm{E}_{\mathrm{s}}$, is given by:

$$
\frac{E_{1, H}^{*}}{E_{s}}=\frac{d \operatorname{Sin} \theta}{(h+d \operatorname{Cos} \theta) b\left\{\frac{d}{A_{d}} \operatorname{Sin}^{2} \theta+\left[\frac{d^{3}}{12 I_{d}}+\frac{2 d}{A_{d}} \chi_{d}(1+v)\right] \operatorname{Cos}^{2} \theta\right\}}
$$

where: $I_{d}$ is the inertia of the cross sectional area of the diagonal beam with respect to the flexural axis.

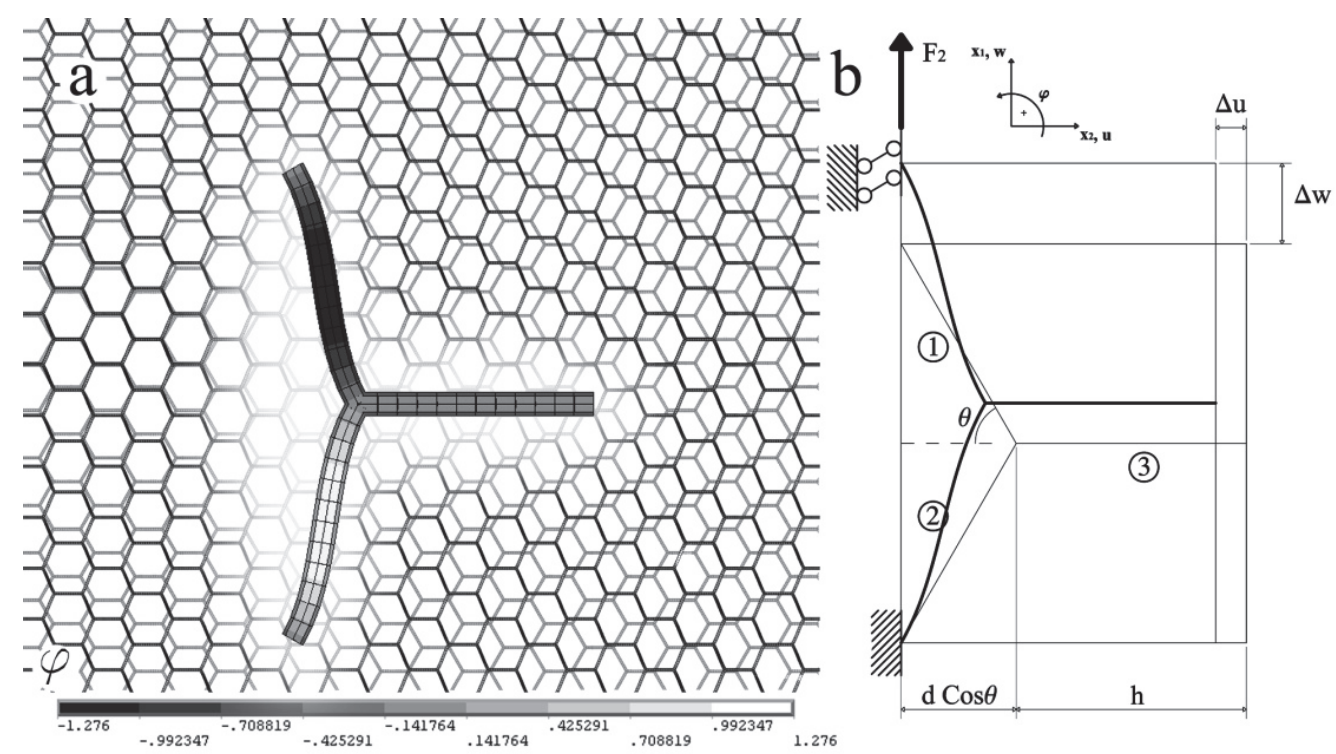

Figure 8: Hexagrid - axial test along $\mathrm{x}_{1}$; a) deformed configuration; b) definition of the RVE.

The stiffness of the hexagrid in the direction $\mathrm{x}_{2}, \mathrm{E}_{2 \mathrm{H}}^{*}$, (Fig. 9), normalised to the Young's modulus of the member solid material $\mathrm{E}_{\mathrm{s}}$, is given by: 


$$
\frac{E_{2, H}^{*}}{E_{s}}=\frac{h+d \operatorname{Cos} \theta}{2 d \operatorname{Sin} \theta b\left[\frac{h}{A_{h}}+\frac{d}{2 A_{d}} \operatorname{Cos}^{2} \theta+\left[\frac{d^{3}}{24 I_{d}}+\frac{d}{A_{d}} \chi_{d}(1+v)\right] \operatorname{Sin}^{2} \theta\right]}
$$

Considering the shear tests (Fig. 10 and 11), the global shear distortion of the unit cell, $\Delta \mathrm{w}$ or $\Delta \mathrm{u}$, is caused by shortening/lengthening of elements subjected to axial forces, by shear deformation of elements under shear forces, and by flexural deflection of elements subjected to bending moments.

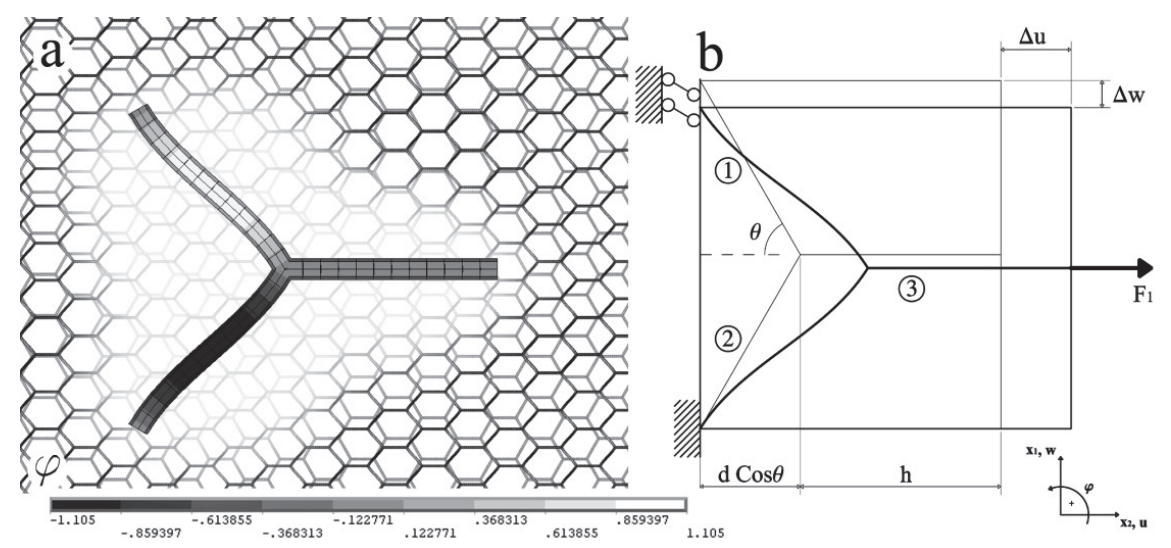

Figure 9: Hexagrid - axial test along $\mathrm{x}_{2}$; a) deformed configuration; b) definition of the RVE.

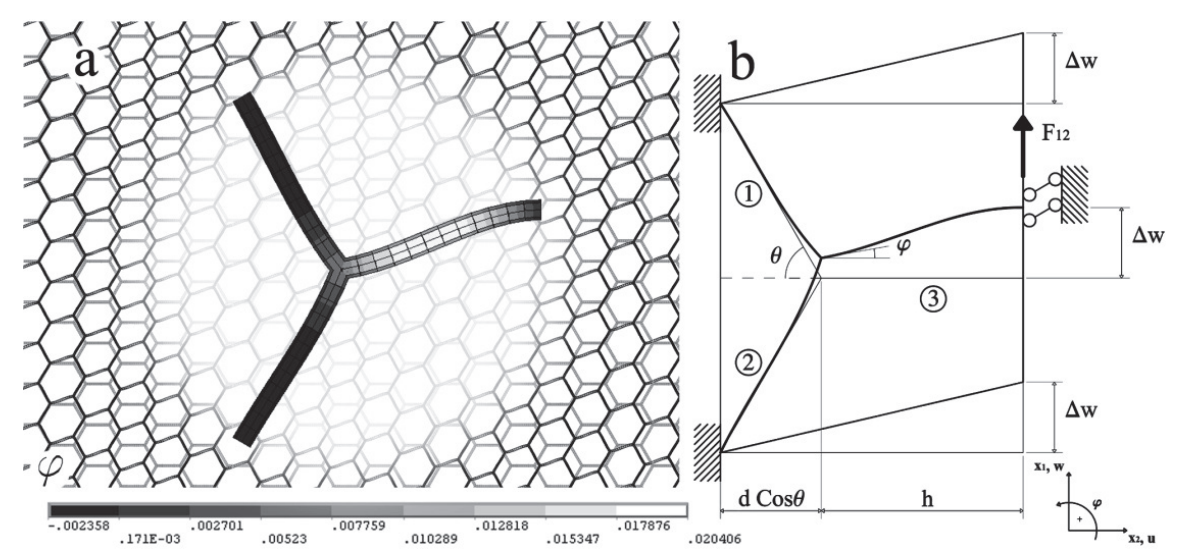

Figure 10: Hexagrid - shear test; a) deformed configuration; b) definition of the RVE.

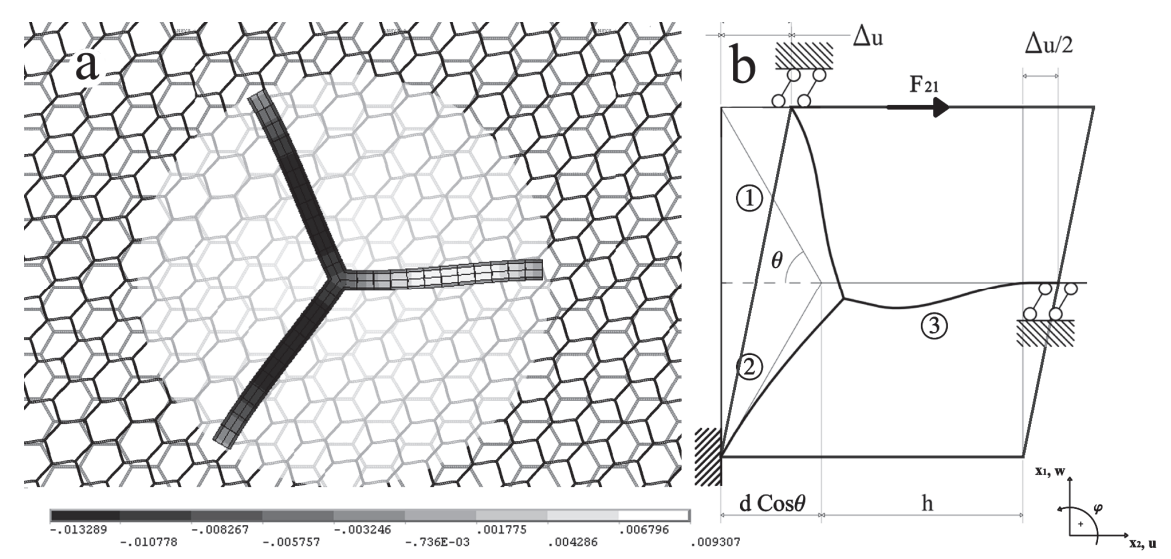

Figure 11: Hexagrid - shear test; a) deformed configuration; b) definition of the RVE. 
Therefore the shear stiffnesses of the hexagrid, $\mathrm{G}^{*}{ }_{12 \mathrm{H}}$ and $\mathrm{G}^{*}{ }_{21 \mathrm{H}}$, normalised to the shear modulus of the member solid material, $G_{s}$, are given by:

$$
\begin{aligned}
& \frac{G_{12, H}^{*}}{G_{s}}=\frac{12 I_{d}(1+v)(h+d \operatorname{Cos} \theta)}{b d h^{5} \operatorname{Sen} \theta}\left\{6 E_{s}^{2} \gamma_{1}+\frac{A_{h} h^{5}\left(1-\frac{I_{h}+\gamma_{1} \gamma_{13}}{h^{3} \gamma_{11}}\right)}{A_{h} h^{2}+24 I_{h}(1+\nu) \chi_{h}}\right\}
\end{aligned}
$$

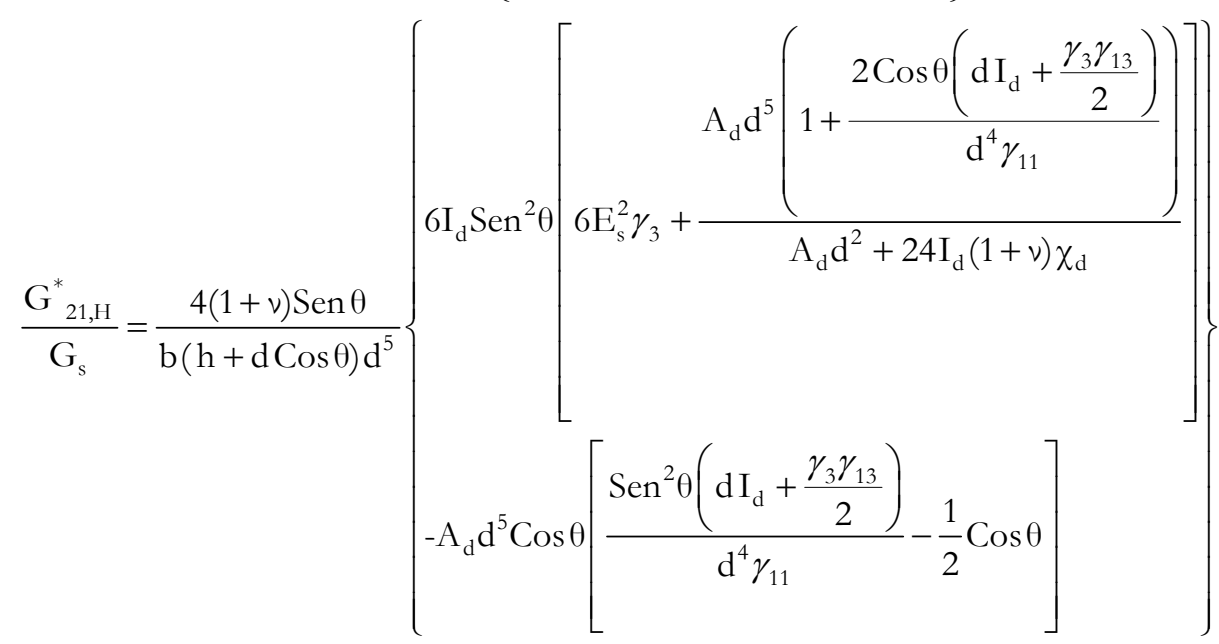

where: $I_{h}$ is the inertia of the cross sectional area of the horizontal beam with respect to the flexural axis, and:

$$
\begin{aligned}
& \gamma_{1}=\frac{I_{h}\left(\frac{\gamma_{h}}{I_{h}} I_{d}+\gamma_{d}+A_{d} d^{2} \operatorname{Sen}^{2} \theta\right)}{d^{3}\left(36 E_{s}^{2} \gamma_{11} \gamma_{12}-\gamma_{2}\right)} \\
& \gamma_{2}=\gamma_{13}\left(\frac{\gamma_{\mathrm{h}}}{2 \mathrm{~h}^{3} \operatorname{Cos} \theta}+\frac{\gamma_{\mathrm{d}}}{\mathrm{d}^{3}}+\frac{\mathrm{A}_{\mathrm{d}} \operatorname{Sen}^{2} \theta}{\mathrm{d}}\right) \\
& \gamma_{3}=\frac{\frac{A_{d} d^{3} I_{h} \operatorname{Cos} \theta-\frac{d I_{h} \gamma_{d}}{\operatorname{Cos} \theta}}{h^{3}}-2 A_{d} I_{d}-\frac{d I_{d} \gamma_{h}}{h^{3} \operatorname{Cos} \theta}}{-36 E_{s}^{2} \gamma_{11} \gamma_{12}+\gamma_{2}} \\
& \gamma_{h}=\frac{12 A_{h} h^{2} I_{h} \operatorname{Cos} \theta}{A_{h} h^{2}+24 I_{h}(1+v) \chi_{h}}, \quad \gamma_{d}=\frac{12 A_{d} d^{2} I_{d} \operatorname{Cos} \theta}{A_{d} d^{2}+24 I_{d}(1+v) \chi_{d}} \\
& \gamma_{11}=\frac{\mathrm{I}_{\mathrm{h}}}{\mathrm{h}^{3}}-\frac{2 \mathrm{I}_{\mathrm{d}} \operatorname{Cos} \theta}{\mathrm{d}^{3}}, \gamma_{12}=\frac{\mathrm{I}_{\mathrm{h}}}{\mathrm{h}^{2}}-\frac{2 \mathrm{I}_{\mathrm{d}} \operatorname{Cos} \theta}{\mathrm{d}^{2}} \\
& \gamma_{13}=2 \mathrm{E}_{\mathrm{s}}^{2}\left(\frac{8 \mathrm{I}_{\mathrm{d}}}{\mathrm{d}}+\frac{4 \mathrm{I}_{\mathrm{h}}}{\mathrm{h}}\right)
\end{aligned}
$$

The Eqs. (13-15) and Eq. (16) only contains geometrical quantities, i.e. the geometrical characteristics of the grid $(\theta$, h, $\mathrm{d})$, and the geometrical properties of the structural member cross sections $\left(A_{h}, A_{d}, I_{h}, I_{d}, \chi_{h}, \chi_{d}\right)$. Therefore $E_{1 H}^{*} / E_{s}, E_{2 H}^{*} / E_{s}$, 
$\mathrm{G}^{*}{ }_{12 \mathrm{H}} / \mathrm{G}_{\mathrm{s}}$, and $\mathrm{G}^{*}{ }_{21 \mathrm{H}} / \mathrm{G}_{\mathrm{s}}$ represent the effective elastic properties of the reference sample (RVE), accounting for the global geometry of the grid and the local geometry of the member cross-sections.

This theoretical approach is the one commonly adopted for 2D cellular solid, based on the definition of a representative volume element (RVE), i.e. the unit statistically representative of an infinite periodic structure.

In order to assess the representativeness of the RVE defined in Fig. 8, 9, 10, 11 and the reliability of the Eqs. (13-16), a sensitivity analysis has been carried out. In particular, axial and shear tests have been executed on grid panels made of periodic arrangements of $\mathrm{k} R$ EEs along $\mathrm{x}_{1}$ and $\mathrm{x}_{2}$ directions, with $\mathrm{k} \in\{1,3,5,7,10,13,15\}$. The overall stiffness values calculated from the analyses have proven to be in very good agreement with the values obtained through the RVE calculations.

\section{Effect of the floor rigid diaphragm}

In [12] the application of the Eqs. (13-16) to the design of a tall building model, with tube hexagonal structure, has initially shown significant discrepancies between the value of the top horizontal displacement calculated according to Eq. 3 and the counterpart obtained from FEM analysis. The main source of this scatter was related to the effect of the rigid floor diaphragm (RD), which provides an additional restraint in the axial deformation mode of the RVE, and, globally, of the structural grid; this, in turn, gives rise to a significant increase of the flexural stiffness of the grid tube structure.

The stiffening effect of the rigid diaphragm can be clarified by looking at Fig. 12, which shows the deformation of three models of hexagonal tube structure under compression loads; each model is characterized by a different number of RDs along elevation, i.e.: a) $\mathrm{RD}$ only at the top of the building; b) $\mathrm{RD}$ at every $9^{\text {th }}$ levels; $\mathrm{c}$ ) $\mathrm{RD}$ at every floor.

The comparison among the deformation modes suggests an analogy with the behaviour of laminated elastomeric bearings: the stiffening effect of $\mathrm{RD}$ on the vertical deformation of building structural grid is analogous to the confinement exerted by the steel interlayer shims on the lateral bulging of the rubber layers; this deformation mode of rubber bearings is accounted for by means of the primary shape factor S1, which, in turn, strongly affects the vertical stiffness of the isolator. The presence of the RD constraints does not affect the shear deformation mode, as also occurs in the response of laminated rubber bearings.

On the basis of the above considerations, two procedures have been outlined for dealing with this problem and improving the accuracy in the evaluation of the vertical stiffness modification factor. The first procedure (appointed as Modified RVE Approach (MRA)) is based on the definition of a new, appropriate mechanical model which explicitly takes into account the RD effect; the second procedure (appointed as Isolator Analogy Approach (IAA)) utilizes the analogy with isolator deformation mode and the concept of primary shape factor.

In the following, for the sake of brevity, only the first approach is illustrated.

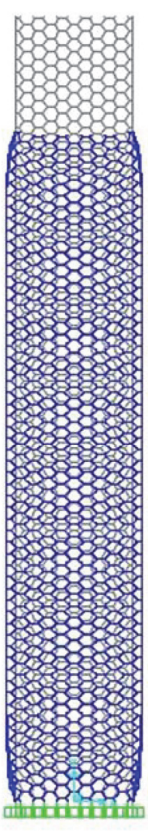

(a)

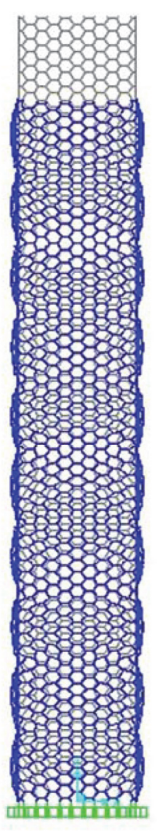

(b)

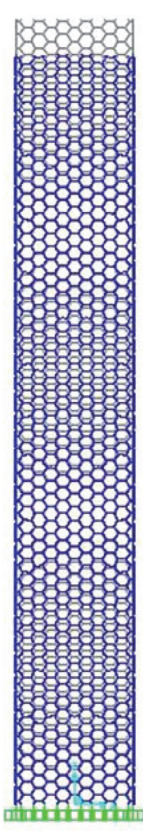

(c)

Figure 12: Effect of the rigid floor diaphragm on Hexagrid tube structures. 


\section{Modified RVE Approach (MRA)}

The so-called Modified RVE approach simply changes the RVE of the hexagonal pattern (from which the Voronoi pattern is subsequently generated) in order to account for the RD additional restraint; of course, the modified RVE strongly depends on the module height, namely on the number of floors (and of RD constraints) occurring along the unit cell.

For a hexagonal patterns with height of the unit cell equal to the interstory height $\left(\mathrm{H}_{\text {unit cell }}=\mathrm{H}_{\text {interstory }}\right)$, the $\mathrm{RD}$ restrains the horizontal dilatations of the module, namely the horizontal displacements of the joints marked with solid circles in Fig. 13; therefore the ends of the diagonal members in the RVE cannot experience horizontal displacements and should be accordingly restrained.

The normalized vertical stiffness for the above structural model is computed through the following relationship:
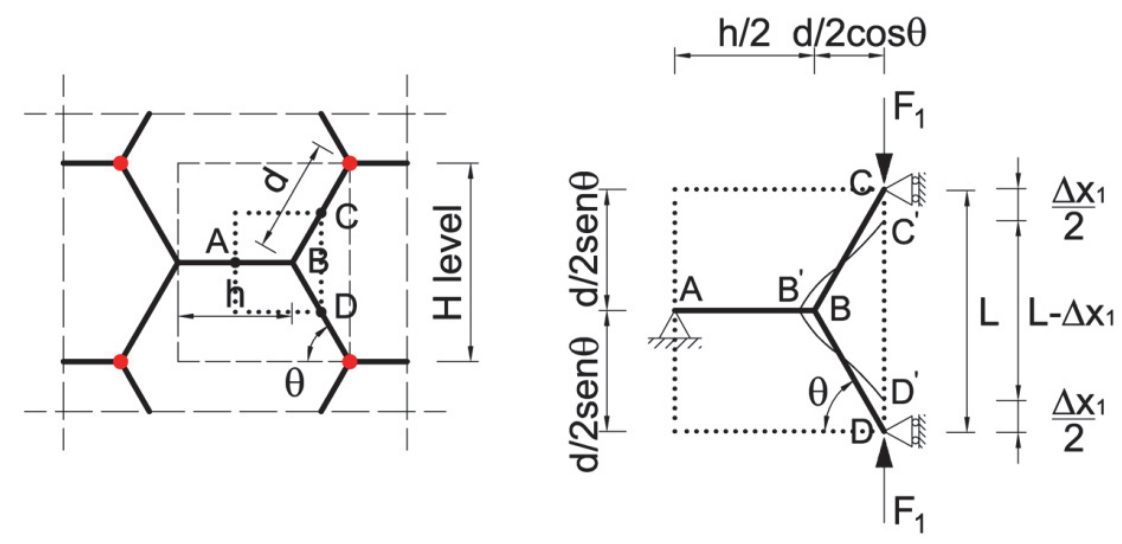

- Diaphragm-Constraint

UNIT CELL

R.V.E.

Figure 13: Hexagrid axial test along $\mathrm{x}_{1}$ : modified RVE accounting for the RD effect.

$$
\frac{E_{1, H}^{*}}{E_{s}}=\frac{1}{(h+d \operatorname{Cos} \theta) b}\left[\begin{array}{l}
\frac{1}{A_{d} \operatorname{Sen} \theta}+\frac{\operatorname{Cos}^{2} \theta\left(\frac{d^{2}}{12 I_{d}}+\frac{2 \chi(1+v)}{A_{d}}-\frac{1}{A_{d}}\right)}{A_{d} \operatorname{Sen} \theta\left(\frac{d^{2} \operatorname{Sen}^{2} \theta}{12 I_{d}}+\frac{2 \chi(1+v) \operatorname{Sen}^{2} \theta}{A_{d}}+\frac{\operatorname{Cos} \theta \operatorname{Sen} \theta}{A_{d}}+\frac{2}{A_{h}}\right)}+ \\
+\frac{2 h \operatorname{Cos}^{2} \theta\left(\frac{d^{2}}{12 I_{d}}+\frac{2 \chi(1+\nu)}{A_{d}}-\frac{1}{A_{d}}\right)}{A_{h} d \operatorname{Sen} \theta\left(\frac{d^{2} \operatorname{Sen}^{2} \theta}{12 I_{d}}+\frac{2 \chi(1+v) \operatorname{Sen}^{2} \theta}{A_{d}}+\frac{\operatorname{Cos} \theta \operatorname{Sen} \theta}{A_{d}}+\frac{2}{A_{h}}\right)}
\end{array}\right]^{-1}
$$

As already observed, the shear stiffness is not affected by the RD action, therefore the normalised shear stiffnesses are still provided by the Eqn. (15) and (16).

In the following, for the sake of simplicity, it is considered: $A_{h}=A_{d}=A$ and $I_{h}=I_{d}=I$, i.e. the same cross section for for all the structural members of the grid horizontal and diagonal members; concerning the geometry of the grid, it is assumed $\mathrm{h}=\mathrm{d}$ and $\theta=\pi / 3$. For this case the Eqns. (15) and (16) are identical, and therefore $G_{12 \mathrm{H}}^{*}=\mathrm{G}^{*}{ }_{21 \mathrm{H}}$.

\section{From HEXAGRID TO VORONOI}

A ccording to the scientific literature [26], the mechanical response of the Voronoi patterns strongly depends on the level of irregularity and on the relative density. Therefore, for the definition of the correction factors which allow to characterize a Voronoi pattern starting from a regular hexagrid, it is necessary to investigate and understand the above effects. 
Recalling the Eqs. (6-7), it is also evident that for a fixed number of cells of the original hexagrid, and for each values of $\alpha$ (i.e. for each level of irregularity) and of $\varrho$ (i.e. for a specific relative density), infinite Voronoi configurations can be generated varying the random parameters $\varphi_{\mathrm{s}}$ and $\vartheta_{\mathrm{s}}$.

The RVE modeling approach used in the previous paragraph for investigating the mechanical properties of the regular honeycomb is not able to account for the irregularities in the Voronoi microstructure. In fact, the Voronoi tessellation shows a non-periodic pattern and the choice of an appropriate, statistically significant, RVE, is impossible, due to a violation of the definition of RVE [32].

Since the randomness in the Voronoi structure at the macroscopic level can produce a wide range of values of the overall mechanical properties, the effect of irregularity and relative density on the mechanical proprieties of the Voronoi patterns should be assessed on a statistical basis. This is the approach suggested by [32] and adopted in the following: instead of prescribing a RVE for executing a single analysis that is statistically representative of the global response, a large set of repeated homogenization analyses are performed on small scale Testing Volume Elements (TVE).

For each specific couple of values of $\rho$ and $\alpha$ (say, $\bar{\rho}$ and $\bar{\alpha}$ ) a set of TVE is generated varying the random variables $\varphi_{\mathrm{s}}$ and $\vartheta_{\mathrm{s}}$. The number of TVE herein considered is large enough to include all pattern irregularities, and, although each single TVE is not able to represent the structure at the macroscale level, the entire set of TVE can be assumed as statistically representative of the whole pattern. Some critical points, therefore, are the definition of the TVE size and of the numerosity of the TVE set; for these aims, some preliminary sensitivity analyses have been carried out, as reported in the following subparagraph.

The axial and shear tests have been performed through finite element (FE) analyses using the computer code SAP2000; the specimens have been modelled as assemblies of Timoshenko beam elements, which include bending, axial and shear deformations. In the FE models, the boundary conditions and the external forces reported in Fig. 14 have been applied in order to perform axial and shear tests.

Through the axial and shear tests, the values of the effective mechanical proprieties of the k-th Voronoi TVE ( $\mathrm{E}^{*} 1, \mathrm{~V}, \mathrm{k}, \mathrm{E}_{2, \mathrm{~V}, \mathrm{k}}$ and $\left.\mathrm{G}^{*}{ }_{12, \mathrm{~V}, \mathrm{k}}=\mathrm{G}^{*}{ }_{21, \mathrm{~V}, \mathrm{k}}\right)$ have been obtained by homogenizing the $\mathrm{FE}$ numerical results, following the relationships:

$$
\begin{aligned}
& \mathrm{E}_{1, \mathrm{~V}, \mathrm{k}}^{*}=f\left(\bar{\varrho}, \bar{\alpha}, \varphi_{\mathrm{s}}, \vartheta_{\mathrm{s}}\right) \\
& \mathrm{E}_{2, \mathrm{~V}, \mathrm{k}}^{*}=f\left(\bar{\varrho}, \bar{\alpha}, \varphi_{\mathrm{s}}, \vartheta_{\mathrm{s}}\right) \\
& \mathrm{G}_{12, \mathrm{~V}, \mathrm{k}}^{*}=f\left(\bar{\varrho}, \bar{\alpha}, \varphi_{\mathrm{s}}, \vartheta_{\mathrm{s}}\right)
\end{aligned}
$$

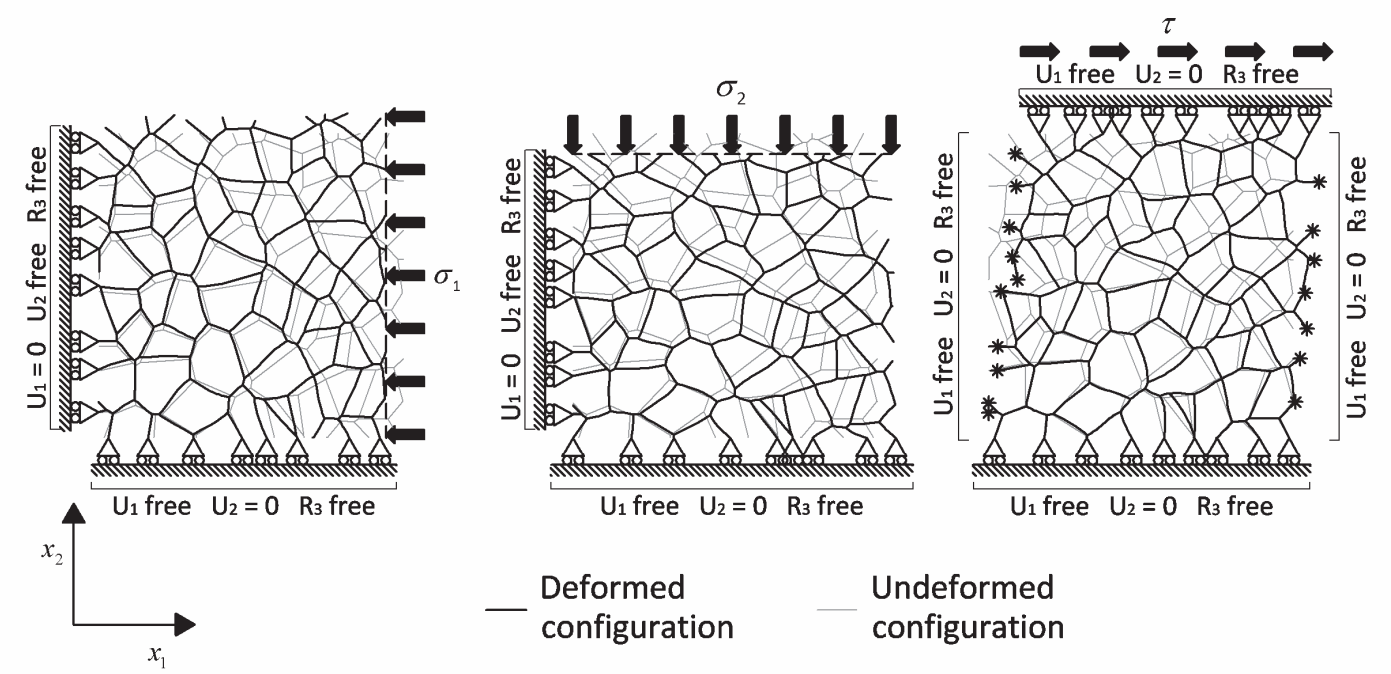

Figure 14: Boundary conditions and external forces adopted in the FE models of the Voronoi specimens.

The ratio of the experimental values $E_{1, \mathrm{~V}, \mathrm{k}}^{*}, \mathrm{E}_{2, \mathrm{~V}, \mathrm{k}}^{*}$ and $\mathrm{G}^{*}{ }_{12, \mathrm{~V}, \mathrm{k}}=\mathrm{G}_{21, \mathrm{~V}, \mathrm{k}}^{*}$, to the original hexagrid counterparts, resulting from of Eq. (17), and Eqs. (14-15), have been computed and appointed as the modification factors of axial and shear stiffness for the k-th TVE, $\eta_{\mathrm{E} 1, \mathrm{k}}, \eta_{\mathrm{E} 2, \mathrm{k}}$ and $\eta_{\mathrm{G} 12, \mathrm{k}}=\eta_{\mathrm{G} 21, \mathrm{k}}$, i.e.: 


$$
\begin{aligned}
& \eta_{\mathrm{E} 1, \mathrm{k}}=\frac{\mathrm{E}_{1, \mathrm{~V}, \mathrm{k}}^{*}}{\mathrm{E}_{1, \mathrm{H}}^{*}} \\
& \eta_{\mathrm{E} 2, \mathrm{k}}=\frac{\mathrm{E}_{2, \mathrm{~V}, \mathrm{k}}^{*}}{\mathrm{E}_{2, \mathrm{H}}^{*}} \\
& \eta_{\mathrm{G} 12, \mathrm{k}}=\frac{\mathrm{G}_{12, \mathrm{~V}, \mathrm{k}}^{*}}{\mathrm{G}_{12, \mathrm{H}}^{*}}
\end{aligned}
$$

Fixed the values $\rho=\bar{\rho}$ and $\alpha=\bar{\alpha}$, the modification factors are functions of $\varphi_{\mathrm{s}}$ and $\vartheta_{\mathrm{s}}$. In force of the probabilistic distribution of the parameters $\varphi_{\mathrm{s}}$ and $\vartheta_{\mathrm{s}}$, Eqs. (4-5), it is possible to assume an equal probability for the occurrence of all the analyzed TVE; then, the probability related to each TVE analysis is:

$$
\begin{aligned}
& p\left(\eta_{E 1, k}\right)=\frac{1}{n} \\
& p\left(\eta_{E 2, k}\right)=\frac{1}{n} \\
& p\left(\eta_{G 12, k}\right)=\frac{1}{n}
\end{aligned}
$$

where $\mathrm{n}$ is the total number of numerical experiments (i.e. of TVE specimens).

Finally, for a Voronoi pattern characterized by $\rho=\bar{\rho}$ and $\alpha=\bar{\alpha}$, the expected (average) values of the modification factors can be calculated through the forms:

$$
\begin{aligned}
& \eta_{\mathrm{E} 1, \mathrm{~A}}(\bar{\varrho}, \bar{\alpha})=\sum_{\mathrm{k}=1}^{\mathrm{n}} \eta_{\mathrm{E} 1, \mathrm{k}} \mathrm{p}\left(\eta_{\mathrm{E} 1, \mathrm{k}}\right) \\
& \eta_{\mathrm{E} 2, \mathrm{~A}}(\bar{\varrho}, \bar{\alpha})=\sum_{\mathrm{k}=1}^{\mathrm{n}} \eta_{\mathrm{E} 1, \mathrm{k}} \mathrm{p}\left(\eta_{\mathrm{E} 1, \mathrm{k}}\right) \\
& \eta_{\mathrm{G} 12, \mathrm{~A}}(\bar{\varrho}, \bar{\alpha})=\sum_{\mathrm{k}=1}^{\mathrm{n}} \eta_{\mathrm{G} 12, \mathrm{k}} \mathrm{p}\left(\eta_{\mathrm{G} 12, \mathrm{k}}\right)
\end{aligned}
$$

Once defined the number $\mathrm{n}$ of random Voronoi specimens (TVE) to be analyzed for collecting statistically significant data, an extensive campaign of numerical tests has been performed, varying the values of irregularity and relative density. In particular, starting from regular hexagonal patterns with the same overall geometry and number of unit cells but variable relative density $\left(\rho_{\mathrm{i}}=0.01,0.05,0.15,0.20,0.25,0.30\right), \mathrm{n}$ specimens have been generated for each value of irregularity (i.e. $\left.\alpha_{i}=0,0.1,0.2,0.3,0.4,0.5,0.6,0.7,0.8,0.9,1\right)$ and for each value of $\rho_{i}$.

\section{Sensitivity analyses}

As previously mentioned, two critical issues have been preliminarly addressed, namely the definition of the TVE size and the definition of the numerosity of the TVE set. For both aims, sensitivity analyses have been carried out.

Concerning the TVE size, it has been assessed that adopting a dimension of 20X18 unit cells for the TVE, the size effect in the results of mechanical tests is negligible for the aim of this work.

The second sensitivity analysis, carried out for establishing a statistically significant number of Voronoi specimens, is discussed in the following.

Considering a Voronoi pattern characterized by the maximum irregularity $(\alpha=1)$ and a low relative density $(\varrho=0.01)$, different number $\mathrm{n}$ of specimens $(\mathrm{n}=10,20,30,40,50,60,70,80)$ have been tested; the average values and standard deviations of the correction factors $\eta_{\mathrm{E} 1}, \eta_{\mathrm{E} 2}$, and $\eta_{\mathrm{G} 12}$ have been calculated and analysed as a function of $\mathrm{n}$. 
The charts in Fig. 15 show the values obtained for $\eta_{\mathrm{E} 1}, \eta_{\mathrm{E} 2}$, and $\eta_{\mathrm{G} 12}$, varying the sample population $\mathrm{n}$ : it can be observed that the standard deviation has a small variation going from 10 to 20 tests, while almost no variation arises increasing the number of specimens beyond 20 .

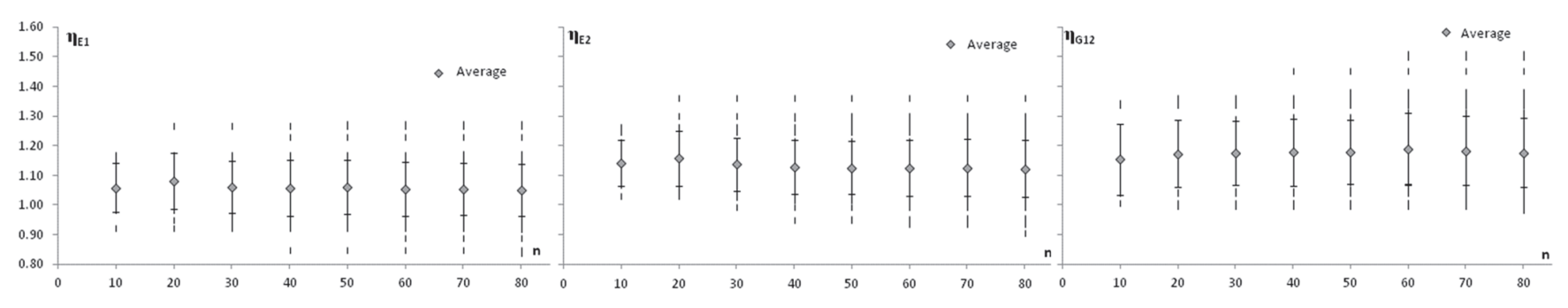

Figure 15: Sensitivity analysis. Effect of the number of specimens: a) $\eta_{\mathrm{E} 1, \mathrm{~A}}$; b) $\eta_{\mathrm{E} 2, \mathrm{~A}}$; c) $\eta_{\mathrm{G} 12, \mathrm{~A}}$.

Based on these results, it has been stated that 20 specimens for each value of irregularity and relative density, are sufficient to obtain analysis results that are statistically significant.

Recalling that 11 values of $\alpha$ and 6 values of $\varrho$ are considered for grasping the effects of irregularity and relative density, and that for each specimen 3 numerical tests are necessary (i.e. axial tests along $\mathrm{x}_{1}$ and $\mathrm{x}_{2}$ directions, and shear test), then a total of 3960 analyses must be performed.

Considering this great amount of analyses, an algorithm that automates the procedure has been defined in the Grasshopper environment, as shown in fig. 16. In particular the algorithm: i) exports the geometry built in grasshopper to a FE computer code (e.g. SAP2000); ii) assigns the defined cross sections to members according to the relative density $\varrho$, iii) applies the external restraints and loads, iv) executes the FE analysis, v) exports the results for subsequent elaboration.

Combining this algorithm with the one previously described for the generation of the Voronoi geometries, the numerical test process is completely automated, with a remarkable reduction of the time consumption.

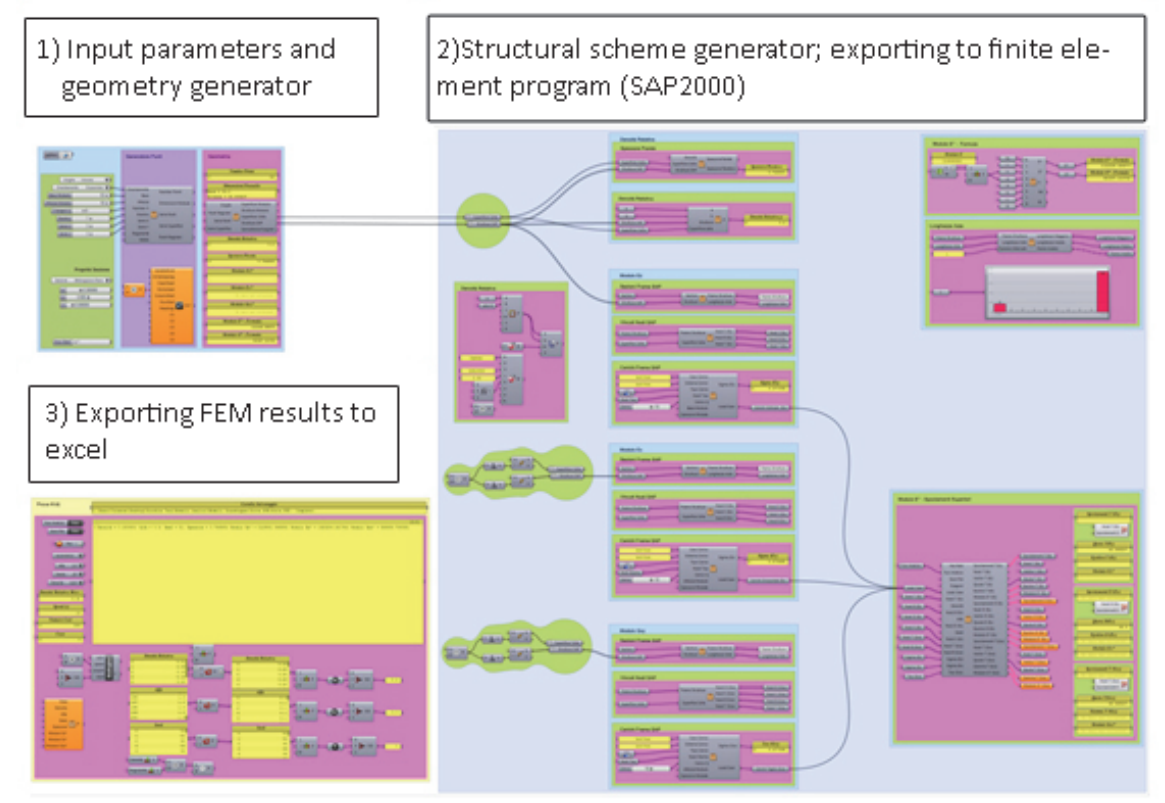

Figure 16: Algorithm defined in Grasshopper environment.

\section{CORRECTION FACTORS FOR VORONOI STRUCTURES}

he results of the parametric FE analysis, carried out by varying both relative density and irregularity, are reported in Fig. 17, 18 and 19; the averages values $\left(\eta_{\mathrm{E} 1, \mathrm{~A}}, \eta_{\mathrm{E} 2, \mathrm{~A}}\right.$ and $\left.\eta_{\mathrm{G} 12, \mathrm{~A}}\right)$ of the twenty correction factors values $\left(\eta_{\mathrm{E} 1, \mathrm{i}}, \eta_{\mathrm{E} 2, \mathrm{i}}\right.$ and $\eta_{\mathrm{G} 12, \mathrm{i}}$ ) obtained for each couple of values $\alpha$ and $\varrho$ (varying $\varphi_{\mathrm{i}}$ and $\vartheta_{\mathrm{i}}$ ) are used as statistical response parameters. 
In particular the average values $\left(\eta_{\mathrm{E} 1, \mathrm{~A}}, \eta_{\mathrm{E} 2, \mathrm{~A}}\right.$ and $\left.\eta_{\mathrm{G} 12, \mathrm{~A}}\right)$ are given: as a function of $\alpha$, set the value of $\varrho$, in Fig. 17; as a function of $\varrho$, fixed the value of $\alpha$, in Fig. 18; as a function of $\varrho$, for different values of $\alpha$, in Fig. 19.

From Fig. 17 it can be observed that, varying $\alpha$ between 0.1 and $0.6, \eta_{\mathrm{E} 1, \mathrm{~A}}$ is always smaller than 1 , meaning that the axial stiffness along $\mathrm{x}_{1}$ of the Voronoi pattern is lower than the one of the regular, "original" hexagonal structure.

In addition, Fig. 18 shows that $\eta_{\mathrm{E} 1, \mathrm{~A}}$ decreases as $\varrho$ increases, i.e. the Voronoi patterns are less stiff than the hexagrid counterparts as the relative density increases. For higher levels of irregularity $(\alpha>0.7)$ and low densities, the Fig. 19 reveals that $\eta_{\mathrm{E} 1, \mathrm{~A}}$ increases and becomes greater than 1 (maximum value equal to $108 \%$ for $\alpha=1$ and $\varrho=0.01$ ); however, for $\varrho$ greater than 0.15 , a reduction of $\eta_{\mathrm{E} 1, \mathrm{~A}}$ can be observed (minimum value equal to $88 \%$ for $\alpha=1$ and $\varrho=0.3$ ). A similar trend can be observed for both $\eta_{\mathrm{E} 2, \mathrm{~A}}$ and $\eta_{\mathrm{G} 12, \mathrm{~A}}$ : for low densities $(\varrho<0.2)$ the correction factors are always greater than $100 \%$, i.e. the Voronoi specimens are always stiffer than the hexagonal counterparts (Fig. 17), while increasing the density ( $\varrho>0.2$ ) both factors $\eta_{\mathrm{E} 2, \mathrm{~A}}$ and $\eta_{\mathrm{G} 12, \mathrm{~A}}$ decrease.
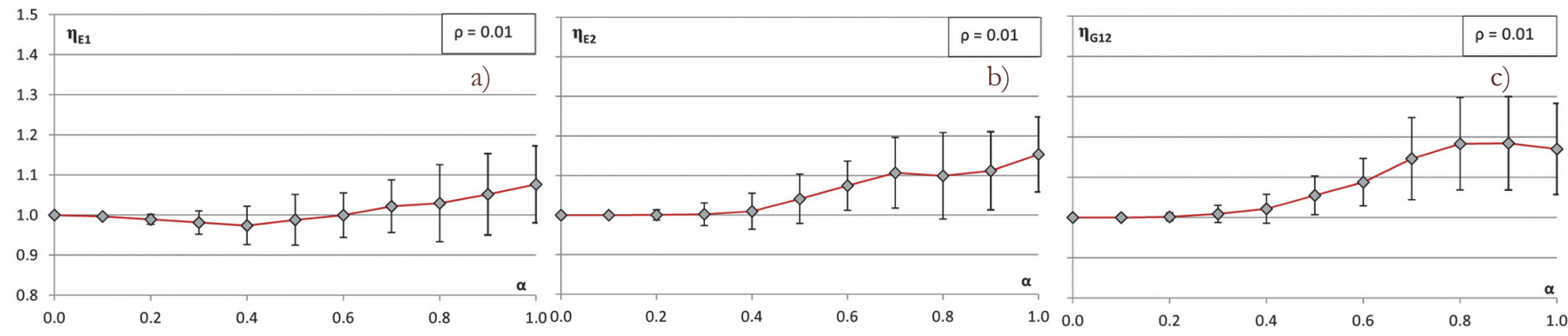

Figure 17: Correction factors vs. irregularity parameter for $\varrho=0.01:$ a) $\eta_{\mathrm{E} 1, \mathrm{~A}}$; b) $\eta_{\mathrm{E} 2, \mathrm{~A}}$; c) $\eta_{\mathrm{G} 12, \mathrm{~A}}$.

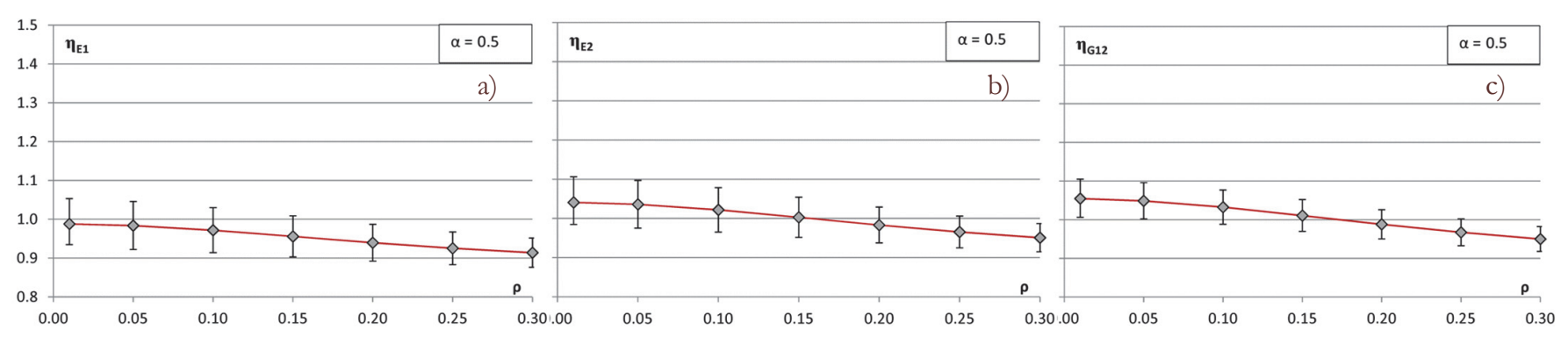

Figure 18: Correction factors vs. relative density for $\alpha=0.5:$ a) $\eta_{\mathrm{E} 1, \mathrm{~A}}$; b) $\eta_{\mathrm{E} 2, \mathrm{~A}}$; c) $\eta_{\mathrm{G} 12, \mathrm{~A}}$.

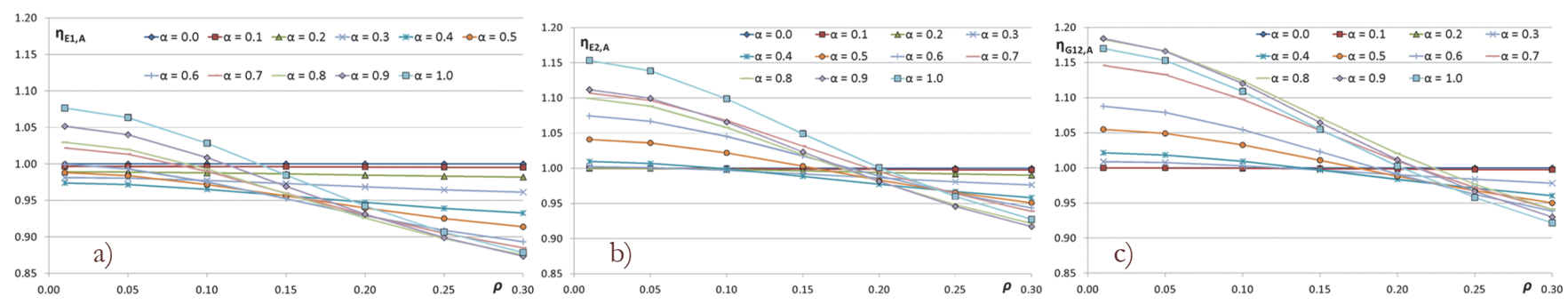

Figure 19: Correction factors vs. relative density for different values of the irregularity parameter: a) $\eta_{\mathrm{E} 1, \mathrm{~A}}$; b) $\eta_{\mathrm{E} 2, \mathrm{~A}}$; c) $\eta_{\mathrm{G} 12, \mathrm{~A}}$.

The Figs. 20 a, b and c report the values of $\eta_{\mathrm{E} 1, \mathrm{~A}}, \eta_{\mathrm{E} 2, \mathrm{~A}}$ and $\eta_{\mathrm{G} 12, \mathrm{~A}}$, respectively, in a three dimensional coordinate system, as a function of $\alpha$ and $\varrho$, and the surfaces that best fit the point distributions. The three surfaces are represented by polynomial expressions, which define $\eta_{\mathrm{E} 1, \mathrm{~A}}, \eta_{\mathrm{E} 2, \mathrm{~A}}$ and $\eta_{\mathrm{G} 12, \mathrm{~A}}$ as functions of $\alpha$ and $\varrho$, i.e.:

$$
\begin{aligned}
& \eta_{\mathrm{i}, \mathrm{A}}=f(\varrho, \alpha)=\mathrm{k}_{00}+\mathrm{k}_{10} \cdot \alpha+\mathrm{k}_{01} \cdot \varrho+\mathrm{k}_{20} \cdot \alpha^{2}+\mathrm{k}_{11} \cdot \alpha \cdot \varrho+\mathrm{k}_{02} \cdot \varrho^{2}+\mathrm{k}_{30} \cdot \alpha^{3}+\mathrm{k}_{21} \cdot \alpha^{2} \cdot \varrho+ \\
& +\mathrm{k}_{12} \cdot \alpha \cdot \varrho^{2}+\mathrm{k}_{03} \cdot \varrho^{3}+\mathrm{k}_{31} \cdot \alpha^{3} \cdot \varrho+\mathrm{k}_{22} \cdot \alpha^{2} \cdot \varrho^{2}+\mathrm{k}_{13} \cdot \alpha \cdot \varrho^{3}+\mathrm{k}_{04} \cdot \varrho^{4}
\end{aligned}
$$


The polynomial coefficients $\left(\mathrm{k}_{\mathrm{ij}}\right)$ for each surface $\eta_{\mathrm{E} 1, \mathrm{~A}}, \eta_{\mathrm{E} 2, \mathrm{~A}}$ and $\eta_{\mathrm{G} 12, \mathrm{~A}}$ are reported in Tab. 1

a)

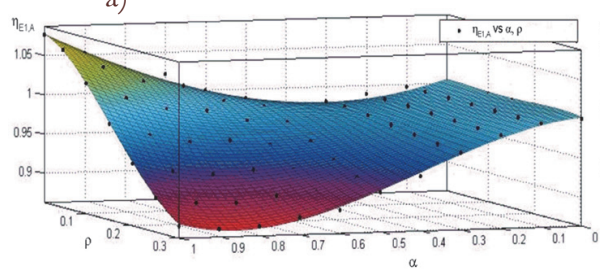

b)

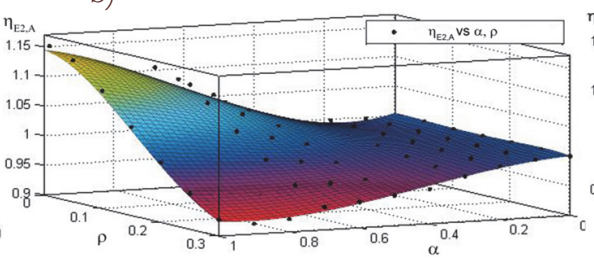

c)

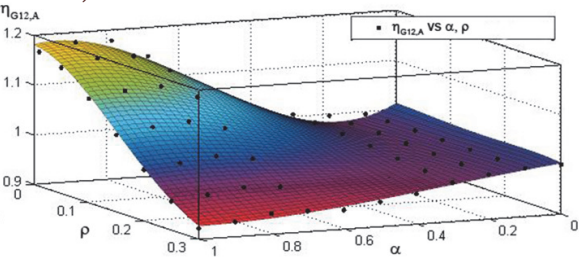

Figure 20: Correction factors vs. relative density and irregularity parameter: a) $\left.\eta_{\mathrm{E} 1, \mathrm{~A}} ; \mathrm{b}\right) \eta_{\mathrm{E} 2, \mathrm{~A}}$ c c) $\eta_{\mathrm{G} 12, \mathrm{~A}}$.

\begin{tabular}{|c|c|c|c|c|c|c|c|c|c|c|c|c|c|c|}
\hline & $\mathrm{k}_{00}$ & $\mathrm{k}_{10}$ & $\mathrm{k}_{01}$ & $\mathrm{k}_{20}$ & $\mathrm{k}_{11}$ & $\mathrm{k}_{02}$ & $\mathrm{k}_{30}$ & $\mathrm{k}_{21}$ & $\mathrm{k}_{12}$ & $\mathrm{k}_{03}$ & $\mathrm{k}_{31}$ & $\mathrm{k}_{22}$ & $\mathrm{k}_{13}$ & $\mathrm{k}_{04}$ \\
\hline$\eta_{\mathrm{E} 1, \mathrm{~A}}$ & 1.0053 & -0.1780 & -0.0049 & 0.3271 & 1.0999 & -0.6239 & -0.0758 & -2.5603 & -5.4090 & 5.0768 & 1.3993 & 0.2842 & 10.5875 & -10.2391 \\
\hline$\eta_{\mathrm{E} 2, \mathrm{~A}}$ & 1.0040 & -0.1634 & -0.0018 & 0.6516 & 1.2630 & -0.7284 & -0.3474 & -3.0570 & -6.2510 & 5.7720 & 1.7380 & 0.5064 & 11.7500 & -11.4600 \\
\hline$\eta_{\mathrm{G} 12, \mathrm{~A}}$ & 1.0130 & -0.3878 & -0.0135 & 1.4150 & 2.0090 & -1.0260 & -0.8586 & -5.1820 & -7.3450 & 7.6560 & 3.1010 & 0.7922 & -13.6000 & -14.9000 \\
\hline
\end{tabular}

Table 1: polynomial coefficients (kij) for the values of $\eta_{\mathrm{E} 1, \mathrm{~A}}, \eta_{\mathrm{E} 2, \mathrm{~A}}$ and $\eta_{\mathrm{G} 12, \mathrm{~A}}$.

\section{DESIGN PROCEDURE}

he design procedure delineated in the second paragraph can now be applied, and the Eq. (3) can be rewritten as:

$$
\delta_{t o p}=\delta_{f l e x .}+\delta_{s b .}=\frac{q H^{4}}{8 E_{1, H}^{*} \eta_{E 1, A} I}+\chi \frac{q H^{2}}{2 G_{12, H}^{*} \eta_{G 12, A} A}=\frac{H}{500}
$$

where: $E^{*}{ }_{1, \mathrm{H}}$ and $\mathrm{G}^{*}{ }_{12, \mathrm{H}}$ can be expressed using the Eqs. (17) and (15-16), respectively; $\eta_{\mathrm{E} 1, \mathrm{~A}}$ and $\eta_{\mathrm{G} 12, \mathrm{~A}}$ are only function of the relative density through Eq. (22), fixed the irregularity degree of the Voronoi patterns (i.e. the value of $\alpha$ ).

Given the overall dimensions of the building (I, A and H) and the external forces (q), in the Eq. (23) the only unknown values are the geometrical properties of the structural members of the Voronoi grid, which appear in Eq. (17), and Eqs. (1516).

The dimension of the members cross section of the Voronoi grid obtained by solving Eq. (23), allow for satisfying the stiffness requirements, i.e. give rise to a Voronoi grid tube which experience a top drift less than $\mathrm{H} / 500 \mathrm{under}$ the design load q. It is worth noticing that the Eq. (23) cannot be solved in closed form, due to the high complexity of the equations involved, thus a numerical solution should be implemented.

\section{Application to a building model}

In order to assess the effectiveness of the design procedure and of the formulations here proposed, an application to a building model is developed. The building model utilized for the design application (Fig. 21) is characterized by plan dimensions and height equal to the 90 -stories Sinosteel International Plaza [33], i.e.: square plan dimension 53x53 m, height $351 \mathrm{~m}$, interstory height $3.9 \mathrm{~m}$. The horizontal wind action considered in the application of the stiffness-based design criterion is a uniform load of $200 \mathrm{kN} / \mathrm{m}$.

The structure has a central core with a simple frame that carries only the tributary gravity loads and does not provide any contribution to the lateral load resistance. On the building perimeter, a Voronoi pattern of structural members has been generated, giving rise to a Voronoi tube structure that carries the tributary gravity loads and the total wind load. The Voronoi pattern is generated starting from a regular hexagonal pattern, with ten hexagonal cells along each plan direction, and applying the maximum level of irregularity (i.e. $\alpha=1$ ) in the Voronoi generation process. 
The cross section area of the Voronoi grid members is calculated by means of Eq. (23); fixing the thickness of the cross section of the Voronoi members, the overall geometrical properties of the building are known. Solving numerically the Eq. (23), a square hollow section (SHS) $1100 x 1100 x 95 \mathrm{~mm}$, made of steel S275 ( $\left.\mathrm{E}_{\mathrm{s}}=210 \mathrm{GPa}, \mathrm{f}_{\mathrm{yk}}=275 \mathrm{MPa}\right)$, is obtained.
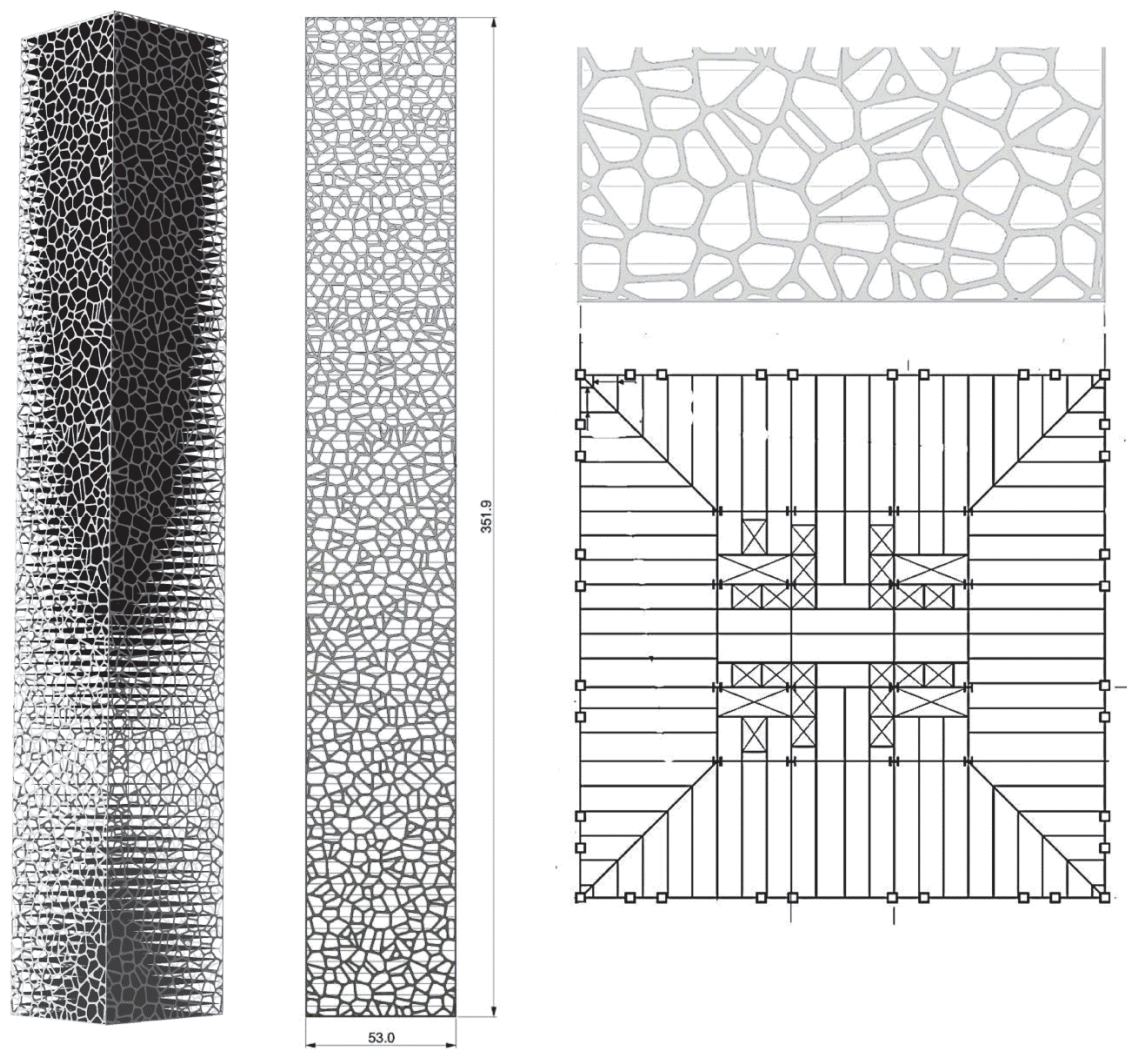

Figure 21: Voronoi building model, elevation and plan.
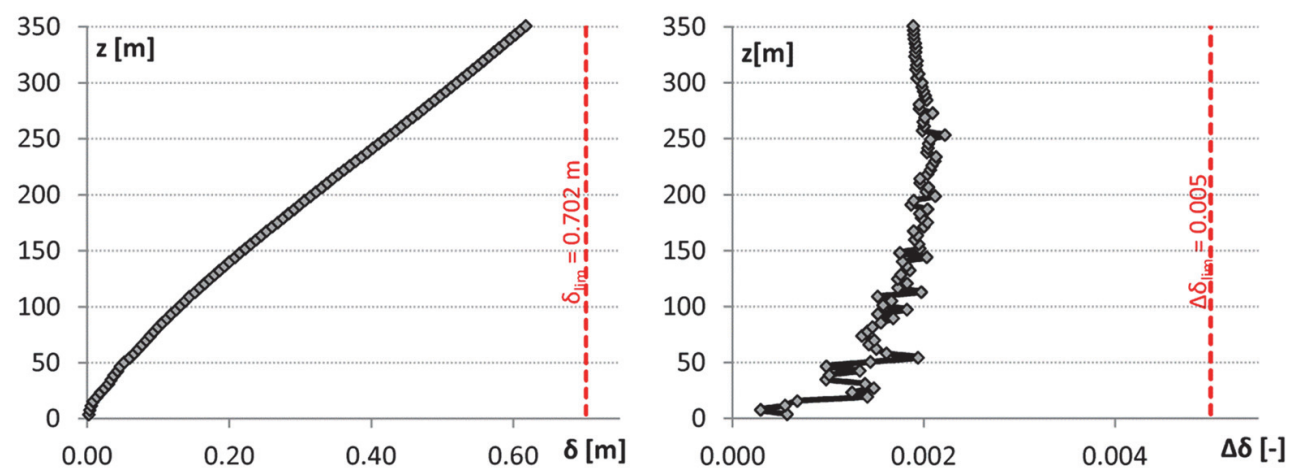

Figure 22: Voronoi building under horizontal loads: lateral displacements, interstory drifts.

\section{FE analysis and assessment of the procedure effectiveness}

The performance of the Voronoi structure designed according to the proposed procedure is checked by means of finite element analysis, using the computer code SAP2000. The structures is modelled as an assemblage of Timoshenko beams, which include bending, axial and shear deformations; at the building base, the joints are fixed and rigid diaphragms constraints are assigned at each floor level. The wind load is modeled as a distribution of lumped forces applied at the centre of gravity of each floor.

The horizontal displacements and the interstory drift along the building height are reported in Fig. 22. It is worth noticing that the top displacement of the building is well within the design limits of H/500. The interstory drifts, as well, are largely 
within a reasonable limit of $\mathrm{h} / 200$, not explicitely imposed during the design procedure, and their distribution along the building height reveals the inherent irregularity of the pattern.

On the baisis of the above analysis results the design procedure proposed in this paper appears as an effective approach for the preliminary member sizing of Voronoi grids adopted for tube structural configuration in tall buildings.

Possible improvements, concerning member size optimization as well as density and/or regularity variations along the building height, i.e. pattern optimization, can be easily obtained through the proposed approach.

\section{DESIGN PROCEDURE EFFECTIVENESS AND VORONOI PATTERNS EFFICIENCY}

A further step in this direction is a recent paper by the first author [34], where different patterns, characterized by both uniform and variable irregularity and/or density are generated, designed and optimized (for the same building model considered in the present paper), with the aim of assessing the efficiency of Voronoi patterns for tall buildings and the effect of irregularity and density (Fig. 23).

The 90 -story building has been divided into 9 stacking modules, each comprising 10 stories: the grid density and irregularity degree are maintained uniform within each macro-module, while they may change form one macro-module to another. A design strategy based on sizing optimization techniques is proposed as either an alternative to, or a refinement of, the preliminary design methods herein suggested; the optimization process is treated with mono-objective genetic algorithms, by minimizing the structural weight and imposing a constraint condition on the lateral stiffness of the building. For each pattern, two structural solutions are considered, one that employs the same cross section for all Voronoi members, and one that uses a different cross section within each macro-module (i.e. 9 cross sections).

The results obtained in [34] can be also utilized for a further effectiveness check of the homogenization based sizing procedure proposed in the present paper. In Fig. 24 a), the structural weight of the pattern considered in the homogenization based sizing procedure (appointed as V1_1, see Fig. 23) is compared to the weight obtained, for the same geometrical pattern, through the member sizing optimization procedure [34], for both the 1-section and 9-section solutions (appointed as V1_1-1 and V1_1-9, respectively).

It can be observed that the homogenization-based solution is heavier than both optimized solutions, in particular, approximately $20 \%$ heavier than the 1 -section solution, and 35\% heavier than the 9 -sections solution. However, it is also worth observing that the comparison among the deformed configurations of the three solutions, depicted in Fig. 24 b), suggests that the lateral stiffness of the homogenization-based solution is larger than the minimum required (i.e. the top drift is smaller than the target value of H/500). On the contrary, both optimized solutions V1_1-1 and V1_1-9 exhibit a top drift equal to the target value.

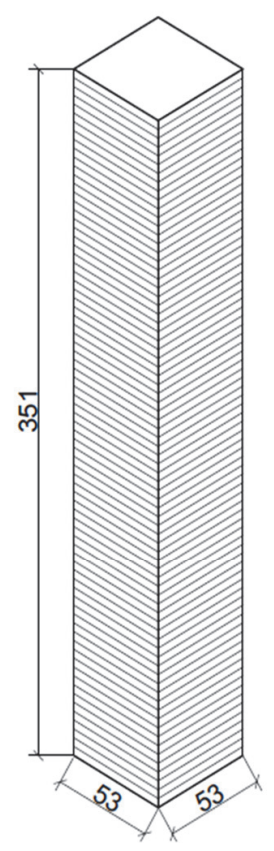

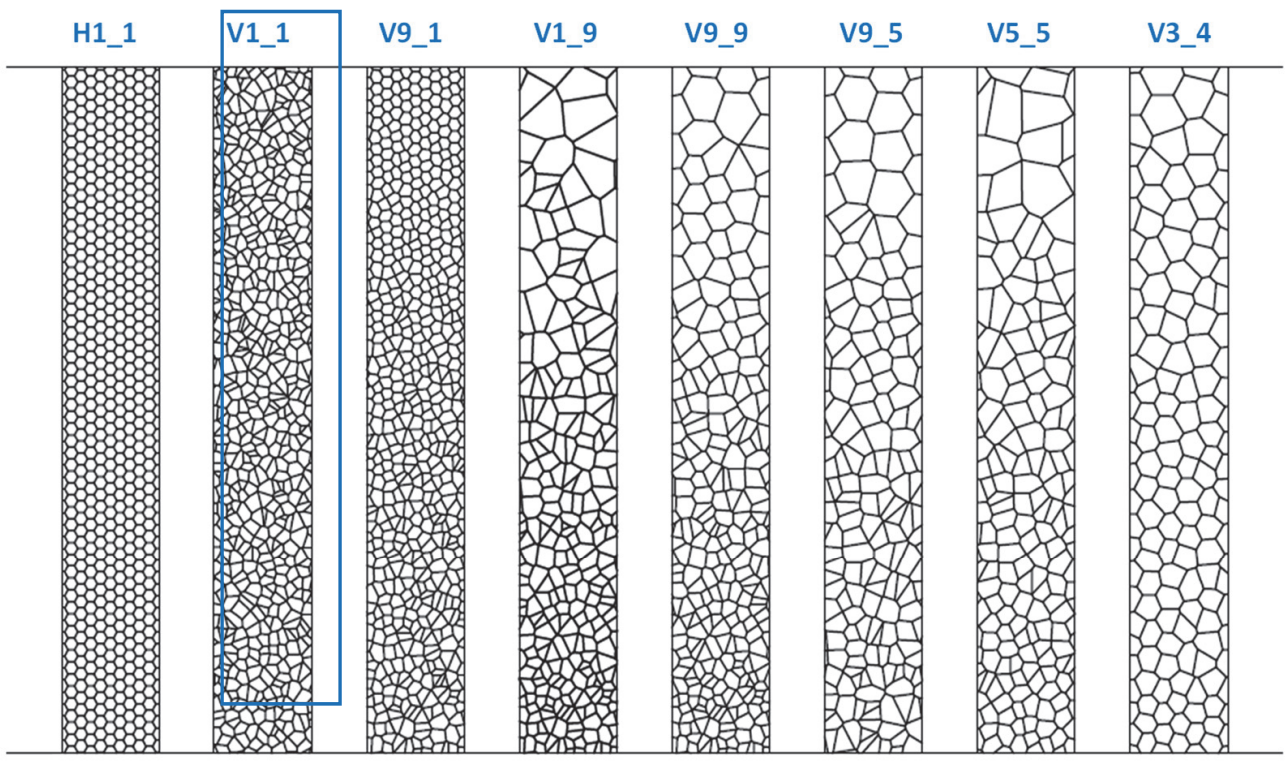

Figure 23: Voronoi patterns: constant/variable irregularity and density. 
Therefore, based on this comparison, it can be stated that the homogenization-based procedure proposed in this paper is suitable for the preliminary design of Voronoi tall buildings, and it gives rise to structural solutions characterized by lateral stiffness approximately 15-20\% larger than the minimum required.

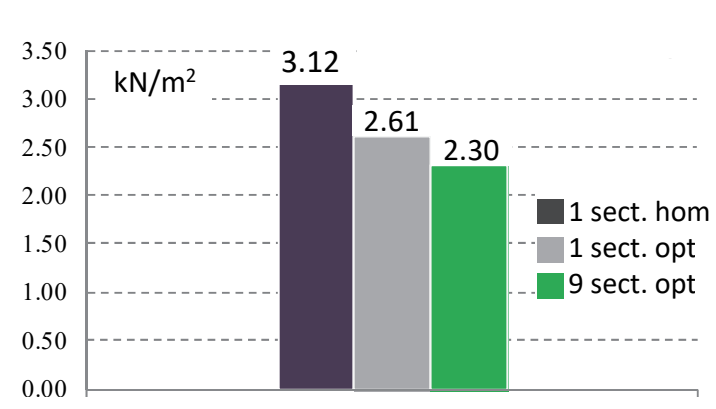

a)

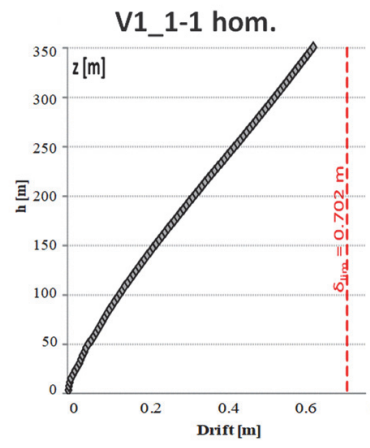

V1_1-9 opt.

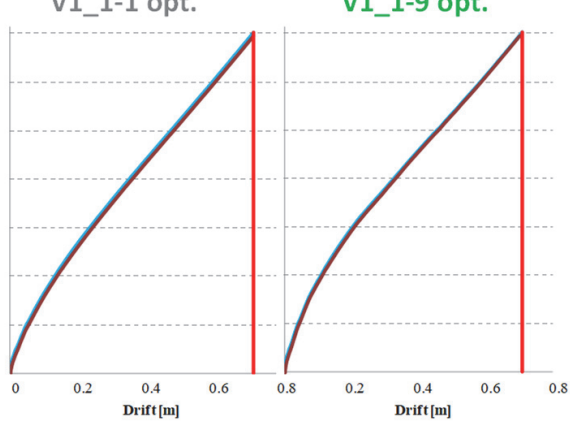

b)

Figure 24: Structural solutions designed for the pattern V1_1: structural weight (a), lateral drifts (b).

Finally, some words should be spent for discussing the Voronoi patterns efficiency, based on the results provided in [34]. In Fig. 25 the parameter utilized for assessing the comparative efficiency of the structural patterns depicted in Fig. 23 is the unit structural weight, i.e. the total weight of the structural steel utilized for the pattern solution divided by the total floor area of the building. In fact, being the structural efficiency a measure of the performance to weight ratio, with the same performance (i.e. top drift equal to $\mathrm{H} / 500$ ), a straightforward comparison of the efficiency of different solutions can be done in terms of structural weight.

Comparing patterns characterized by the same density, uniform along height, and by different irregularity degrees (either constant or variable along the height), it can be observed that the structural weight generally decreases as irregularity increases. In the case of uniform density along elevation, the 9-sections design solutions are usually lighter than the 1-section counterparts; in patterns characterized by variable grid density, on the contrary, the two solutions have almost the same weight, and in some cases (V1_9, V9_5) the 1-section design is even the lightest. A quite narrow range of weight going from 2.4 to $3.2 \mathrm{kN} / \mathrm{m}^{2}$, i.e. quite comparable efficiency, has been obtained for all patterns; however, they are 1.5 to 3.5 times heavier than triangular patterns (diagrids, $\mathrm{w}=0.9-1.3 \mathrm{kN} / \mathrm{m}^{2}$ ) designed and optimized for the same building model [35].

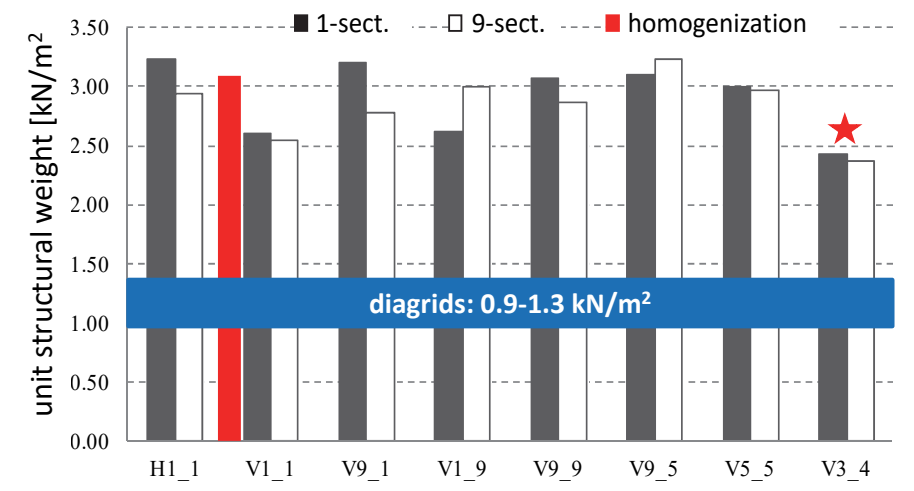

Figure 25: Structural weight of Voroni patterns: 1-section and 9-sections solution.

Of course, a key aspect for real-world applications is the constructability of the patterns. For the patterns V1_1, V9_5, V5_5, V3_4 the weight of the two solutions, 1- and 9-sections, is quite similar. This observation is of great importance from the construction point of view. In fact, the adoption of a single cross section for all members leads to remarkable simplification and economy in the design, fabrication and erection of the structure, and in particular of the connections. A preliminary assessment of these aspects, not reported here for the sake of brevity, is being developed, with a cost-efficiency index proposed for taking into account both mechanical efficiency and practical constructability of the Voronoi patterns. The pattern V3_4 (the last one in Fig. 23 and in the bar chart of Fig. 25, where it is also highlighted by the red star), has been generated for both weight and cost efficiency: in fact, it exhibits a slighter variation of both density and irregularity than the other patterns, though preserves a complex and irregular appearance. 


\section{CONCLUSIONS}

I $\mathrm{n}$ this paper, non regular patterns based on Voronoi diagrams have been considered as structural grid for tall building façades. After having discussed the procedure for the generation of Voronoi diagrams, the authors have defined a methodology for the mechanical characterization and the homogenization process of a Voronoi structural grid. Finally a design procedure has been proposed and applied to a model building.

The approach utilized for the mechanical assessment of the Voronoi grid is based on the concept of RVE (representative volume element), but is developed on a statistical basis in order to take into account the inherent irregularity, non periodicity, and randomness of the grid. The peculiar aspects related to the building scale and behavior, such as the presence of rigid floor diaphragm, are explicitly accounted for, reflecting in a non-negligible stiffening effect on the grid global behavior. The design procedure has been validated trhough the assessment of the structural response of the designed solution and the comparison with structural solutions obtained by means of member sizing optimization for the same pattern.

The homogenization-based design procedure seems particularly useful for the preliminary design; in fact, it allows for defining the cross sections of a very large number of structural members, assembled according to an apparently random grid, by means of simple relationships. Of course, structural analysis of the discrete structural grid is still necessary in the phase of refined design and optimization. However, the authors stress the usefulness of a straightforward tool for the initial sizing phase of a non conventional structural pattern.

The study presented in this paper is part of a wide research, aimed to explore the non-conventional, bio-inspired patterns, alternative to the diagrid, to be used as façade structural grids for tall buildings. In this paper the theoretical background for providing a common methodology in dealing with non-conventional patterns for tube-like structures has been presented; further, the method has also been translated into a simplified tool for the preliminary design and structural member sizing. Within the framework of the proposed approach, it is possible to deal with geometrical patterns characterized by density and/or irregularity degree variable along the building height. Finally, member size optimization, best tuning the strength and stiffness along the elevation, can be obtained with small effort and retaining the conceptual consistency of the procedure. In the author's opinion, a worthy aspect of novelty of the research is the definition of a framework that embraces an almost endless variety of structural configurations, going from the traditional square/rectangular frame, to the diagrid, hexagrid, Voronoi, foam/bubbles trusses, and beyond. Moreover, absolutely novel is the transfer of a methodological approach typical of the material engineering discipline to the context of the structural engineering, particularly the structural engineering of tall buildings. Therefore, the research constitutes an example of cross-fertilization between material engineering and architecture - strucural engineering, which goes well beyond the nature-inspired forms of contemporary architecture, since it provides a repertoire of objects (patterned structural solutions) and the tools for dealing with them from the analysis and design viwpoints.

\section{REFERENCES}

[1] Parker, D. and Wood, A. ed. (2013). Structural possibilities, In: The Tall Buildings Reference Book. New York: Routledge; pp. 213-224.

[2] Moon, K.S., Connor, J.J., Fernandez, J.E. (2007). Diagrid structural system for tall buildings: characteristics and methodology for preliminary design, Struct. Des. Tall Spec. Build., 16, pp. 205-230.

[3] Mele, E., Toreno, M., Brandonisio, G., De Luca, A. (2014). Diagrid structures for tall buildings: case studies and design considerations, Struct. Des. Tall Spec. Build., 23, pp. 124-145.

[4] Montuori, G.M., Mele, E., Brandonisio, G., De Luca, A. (2014). Secondary bracing systems for diagrid structures in tall buildings, Eng. Struct., 75, pp. 477-488.

[5] Montuori, G.M., Mele, E., Brandonisio, G., De Luca, A. (2014). Geometrical patterns for diagrid buildings: Exploring alternative design strategies from the structural point of view, Eng. Struct., 71, pp. 112-127.

[6] Perez, G.A. and Gomez, M.F. (2009). Natural structures: strategies for geometric and morphological optimization, Proc. Symposium Int. Ass. for Shell and Spatial Structures (IASS), Valencia.

[7] Hensel, M., Menges, A., Weinstock, M. ed. (2004). Emergence: Morphogenetic Design Strategies. Architectural Design, London: Wiley.

[8] Gibson, L.J. and Ashby, M.F. (1997). Cellular Solids: structure and properties, Cambridge, Cambridge University Press, 2nd ed. 
[9] Fraldi, M., Cowin, S.C. (2004). Inhomogeneous elastostatic problem solutions constructed from stress-associated homogeneous solutions, J. Mech. Phys. Solids, 52, pp. 2207-2233.

[10] Lakes, R. (1993). Materials with structural hierarchy, Nature, 361, pp. 511-515.

[11] Voronoi, G. (1908). Nouvelles applications des paramètres continus à la théorie des formes quadratiques, J. für die Reine und Angewandte Mathematik, 133, pp. 97-178.

[12] Montuori, G.M., Fadda, M., Perrella, G., Mele, E. (2015). Hexagrid - hexagonal tube structures for tall buildings: patterns, modeling, and design, Struct. Des. Tall Spec., 24, pp. 895-940.

[13] Kwan, A.K.H. (1994). Simple method for approximate analysis of framed tube structures, J Struct Eng 120(4), pp. 1221-1239.

[14] Hashin, Z. and Shtrikman, S. (1996). A variational approach to the theory of elastic behaviour of multiphasematerials, J. Mech. Phys. Solid, 11, pp. 127-140.

[15] Burry, J. and Burry, M. (2010). The New Mathematics of Architecture. New York, Thames \& Hudson.

[16] Aurenhammer, F. (1991). Voronoi Diagrams - A Survey of a Fundamental Geometric Data Structure, ACM Computing Surveys (CSUR), 23(3), pp. 345-405.

[17] Wigner, E. and Seitz, F. (1993). On the constitution of metallic sodium, Phys. Res. 43, pp. 804-810.

[18] Bock, M., Tyagi, A.K., Kreft, J.U., Alt, W. (2010). Generalized Voronoi tessellation as a model of two- dimensional cell tissue dynamics, Bull. Math. Biol. 72, pp. 1696-1731.

[19] Silva, M.J. and Gibson, L.J. (1997). The effects of non-periodic microstructure and defects on the compressive strength of twodimensional cellular solids, Int. J. Mech. Sci., 39, pp. 549-563.

[20] Vajjhala, S., Kraynik, A.M., Gibson, L.J. (2000). A cellular solid model for modulus reduction due to resorption of trabeculae in bone, J. Biomech. Eng. - T. ASME, 122, pp. 511-515.

[21] Hahn, C. (2010). eVolo Skyscraper Competition entry "Use Arrangement". Available at http://www.evolo.us/architecture/a-city-within-a-skyscraper-for-battery-park/.

[22] Beghini, L.L., Beghini, A., Katz, N., Baker, W.F., Paulino, G.H. (2014). Connecting architecture and engineering through structural topology optimization, Eng. Struct. 59, pp. 716-726.

[23] LAVA. Bionic Tower. (2007). Available at: http://www.l-a-v-a.net/projects/bionic-tower.

[24] Zheng, Z., Yu, I., Li, J. (2005). Dynamic crushing of 2D cellular structures: A finite element study, Int. J. Impact Eng. 32, pp. 650-664.

[25] Fazekas, A., Dendievel, R., Salvo, L., Bréchet, Y. (2002). Effect of microstructural topology upon the stiffness and strength of 2D cellular structures, Int. J. Mech. Sci., 44, pp. 2047-2066.

[26] Zhu, H.X., Hobdell, J.R., Windle, A.H. (2001). Effects of cell irregularity on the elastic properties of 2D Voronoi honeycombs. J. Mech. Phys. Solids, 49, pp. 857-870.

[27] Silva, M.J., Gibson, L.J., Hayes, W.C. (1995). The effects of non-periodic microstructure on the elastic proprieties of two-dimensional cellular solids, Int. J. Mech. Sci. 37, pp. 1161-77.

[28] Li, K., Gao, X.L., Subhash, G. (2005). Effects of cell shape and cell wall thickness variations on the elastic properties of two-dimensional cellular solids, Int. J. Solids Struct, 42, pp. 1777-1795.

[29] Li, K., Gao, X.L., Roy, A. (2003). Micromechanics model for three-dimensional open-cell foams using a etrakaidecahedral unit cell and Castigliano's second theorem, Compos. Sci. and Tech., 63, pp. 1769-1781.

[30] deMeijer, J.H.M. (2012). Lateral stiffness of hexagrid structures. Master's thesis. Eindhoven University of Technology Department of the Built Environment Structural Design.

[31] Nemat-Nasser, S., Hori, M. (1999). Micromechanics: Overall Properties of Heterogeneous Materials, North-Holland Elsevier, 2nd Edition.

[32] Hohe, J., Beckman. (2012). Probabilistic homogenization of hexagonal honeycombs with perturbed microstructure, Mech. Mater., 49, pp. 13-29.

[33] Fu, X.Y., Gao, Y., Zhou, Y., Yang, X. (2012). Structural Design of Sino Steel International Plaza, Proc. of 9th CTBUH World Congress, Shanghai.

[34] Mele, E., Simeone, A., Tomei, V. (2018). Efficiency vs. Irregularity in non-conventional structural patterns: the case of tall buildings, Proc. of the IASS Symposium Creativity in Structural Design. July 16-20, MIT, Boston, USA.

[35] Tomei, V., Imbimbo, M., Mele, E. Optimization of structural patterns for tall buildings: the case of diagrid, Eng. Struct., 171, pp. 280-297. 